\title{
Parents with an Unemployed Adult Child: Labor Supply, Consumption, and Savings Effects
}

\author{
Kathryn Anne Edwards and Jeffrey B. Wenger
}

Project \#: R-UM17-18 


\title{
Parents with an Unemployed Adult Child: Labor Supply, Consumption, and Savings Effects
}

\author{
Kathryn Anne Edwards \\ RAND Corporation
}

Jeffrey $B$. Wenger

RAND Corporation

September 2017

\author{
Michigan Retirement Research Center \\ University of Michigan \\ P.O. Box 1248 \\ Ann Arbor, MI 48104 \\ www.mrrc.isr.umich.edu \\ (734) 615-0422
}

\section{Acknowledgements}

The research reported herein was performed pursuant to a grant from the U.S. Social Security Administration (SSA) funded as part of the Retirement Research Consortium through the University of Michigan Retirement Research Center Award RRC08098401-09. The opinions and conclusions expressed are solely those of the author(s) and do not represent the opinions or policy of SSA or any agency of the federal government. Neither the United States government nor any agency thereof, nor any of their employees, makes any warranty, express or implied, or assumes any legal liability or responsibility for the accuracy, completeness, or usefulness of the contents of this report. Reference herein to any specific commercial product, process or service by trade name, trademark, manufacturer, or otherwise does not necessarily constitute or imply endorsement, recommendation or favoring by the United States government or any agency thereof.

\section{Regents of the University of Michigan}

Michael J. Behm, Grand Blanc; Mark J. Bernstein, Ann Arbor; Shauna Ryder Diggs, Grosse Pointe; Denise Ilitch, Bingham Farms; Andrea Fischer Newman, Ann Arbor; Andrew C. Richner, Grosse Pointe Park; Ron Weiser, Ann Arbor; Katherine E. White, Ann Arbor; Mark S. Schlissel, ex officio 


\title{
Parents with an Unemployed Adult Child: Labor Supply, Consumption, and Savings Effects
}

\begin{abstract}
The risk of labor market, health, and asset-value shocks comprise profound retirement savings challenges for older workers. Parents, however, may experience added risk if their children experience adverse labor market shocks. Prior research has shown that parents support their children financially through an unemployment spell. In this paper, we also provide evidence of financial support from parents and investigate if this financial support is accompanied by adjustments to parental labor supply, program participation, consumption, or savings behavior. With longitudinal data on parents and children from the Panel Study of Income Dynamics, we use within-parent variation in behavior to identify the effect of a child's labor market shock on parental outcomes. We find results vary by the parent's age: Parents younger than 62 years old increase labor supply and decrease savings rates, all parents reduce assets and usual food consumption.
\end{abstract}

\section{Citation}

Edwards, Kathryn Anne, and Jeffrey B. Wenger. 2017. "Parents with an Unemployed Adult Child: Labor Supply, Consumption, and Savings Effects." Ann Arbor MI: University of Michigan Retirement Research Center (MRRC) Working Paper, WP 2017-368. http://mrrc.isr.umich.edu/wp368/

\section{Authors' acknowledgements}

The authors thank Jeff Smith, Nora Gordon, Kasey Buckles, Elira Kuka, Na'ama Shenav, and Stephanie Rennane for comments. 


\section{Introduction}

Prior research establishes that families often serve as the first line of defense against adverse events - for example, spouses enter the labor force or increase their hours of work when a partner is laid-off (Cullen and Gruber, 2000), grandparents can provide child care or loans when a child is sick (Bianchi et al., 2010), and parents respond to the economic needs of their children through various forms of assistance, such as offering co-residence or sending money (Wiemers, 2014; Kaplan, 2012; McGarry, 2016; Edwards, 2017). It is generally assumed, either explicitly or implicitly, that the providers of assistance are not made worse off by helping their family members if for no other reason than they willingly elect to do so.

However, the voluntary aspect of the provision of family assistance does not make it costless. Parents are not forced to help their children; in some instances parents will not help children who have reached what the parent deems to be inde-pendence. More typically, parents help children for a variety of reasons - love and a familial obligation to their children being the most obvious - consequently, not helping them during a period of hardship provides disutility. Alternately, parents may help adult children as part of a quid pro quo or exchange motive. Parents understand that their children will take care of them late in life, consequently, they will help children throughout adulthood. The question for us is not the motives of parents and children, but estimating the impacts when parents choose to help. Ultimately, are parents financially prepared to help? This is especially interesting because costs occur on two temporal margins. The first is the current-period cost of provision, such as the amount of money a parent decides to give or lend to a child. The second is the future liability, or the cost of risk sharing, such as the need to send money during future spells if they occur. Prior research is insufficient to determine whether parental liabilities on these margins are trivial. This is a serious shortcoming in the research, because large costs could alter the efficiency and effectiveness of risk-sharing within families.

In this paper, we directly approach the potential costs of aiding family members. We 
examine parental behavior in the year that an adult, nonresidential child experiences an unemployment spell. We measure the concurrent changes to the parent's consumption, income, and savings. We use 1985-2013 waves of the Panel Study on Income Dynamics, a longitudinal dataset that allows for parent-child linkages across households within the same wave of the survey. Given that we can observe parents over long periods, we regress an adult child's unemployment on parental outcomes and include parent, year, and parent-age fixed effects, which control for unobserved individual, time-period and life-cycle characteristics of the parents that could be correlated with job loss of the children. Identification comes from within-parent variation in outcomes and the incidence of a child's unemployment spell.

Our analysis includes four classes of dependent variables that attempt to quantify the flow of financial assistance to children and any concurrent changes in parents' consumption, income, or savings. Each category is only partially measured; specifically, we examine the effect of a child's unemployment on the following parental behaviors:

- probability that a parent sends a cash transfer,

- food consumption,

- parental labor supply,

- public program participation,

- savings rates, and

- asset values.

We do, however, find results in each category, though they vary by the age and situation of the parent.

We corroborate the findings of previous studies and show that parents are more likely to send a cash transfer to a child if they have an unemployed child. Children receiving transfers are more likely to be younger, unmarried, and childless. Separately, and not conditional of transfer sending, we find large drops in usual household food consumption, the only consistently 
measured consumption variable available, for parent households of all ages. In addition, we show labor supply increases for younger, working-age parents (measured either individually or as a household total) during the year of a child's spell. We find slight changes in program participation in Social Security, and no changes in food stamps (Supplemental Nutrition Assistance). Further, we find that younger mothers' pension contribution rates and older mothers' asset values drop in the year of the spell.

The myriad measures examined here are still only partial measurements of the extent of financial assistance provided to unemployed workers by parents and the effect it has on parents, as it is limited by what we observe in the survey. The array of significant changes to parent behavior detected in our study, however, suggests that the costs incurred providing family assistance and the effects of risk bearing may be large. A parent who willingly changes her behavior in order to help a child, though it may be optimal from the point of view of her utility, may still be suboptimal in the distribution and cost of risk in the economy. Given the state of financial insecurity among working-age population and retirement security of near-retired population, suboptimal distribution of risk is a larger concern.

\section{Data}

The Panel Study of Income Dynamics (PSID) is a nationally representative sample of 5,000 U.S. households surveyed annually survey from 1968-1996 and biennially from 1997-2011. It follows original sample members, their descendants, and co-resident relatives over time. The PSID sample grows every year as children of the respondents move out and form their own households, which are added to the panel. This unique sampling frame enables us to see detailed information on parents and their nonresident children concurrently for long periods of time. While the level of detail afforded by family lineage is a key advantage to using the PSID, it has two major caveats relevant for our analysis.

First, while members of the original 1968 sample and their biological descendants are 
continuously followed, family members of those descendants are not. For example, a woman moves out of her parents' house (in the PSID sample), gets married, and has a child. Her child, partner, and self are in the PSID. Her husband's parents are not. If she gets divorced and moves out, she and her child remain in the PSID, but her ex-husband does not. In general, a divorce or partner dissolution in which a nonsample member moves from the house means that that member will be omitted in future surveys. We, therefore, miss parent-child relationships of divorced or separated parents who are not living with the member of the household biologically linked to the original PSID respondent. This is a larger issue for fathers, since mothers are considerably more likely to maintain custody of children.

In addition, the PSID does not collect equal amounts of information on everyone in the household. The full household roster is asked a set of basic demographic and status questions, but detailed information, such as labor supply, is only gathered about the head in early waves, and only heads and spouses in later waves. If an adult moves in with a family member, the move is observed, but the detail is lost. Hence, we cannot detect if a worker became unemployed and moved back in with family because he will no longer be a head of household, and will not report the prior year's labor force information. Hence, our analysis excludes any study of co-residence.

\section{$2.1 \quad$ Mothers}

From the full PSID sample, we create an analytical sample of 38,004 person-year observations of mothers matched to independently living adult children between 1985-2013. ${ }^{1}$ We use mothers because we are able to match them to children at a much higher rate than fathers. With the exception of individual labor supply, all of the dependent variables that we measure are household summaries and would capture any changes to partner behavior. Hence, the only excluded parents from our sample are single or divorced fathers. Table 1 summarizes all of the matched mothers in our sample, together and separated into three age

\footnotetext{
${ }^{1}$ Details of the matching process are discussed in Appendix B.
} 
groups: working age (younger than 62 years old), the retirement window2 (ages 62 to 70), and retired (older than 70). We divide the sample in this way to acknowledge the differences in financial resources, or sources of financial resources, that individuals have before and after they retire. For example, 70.3 percent of working-age moms self-report their current employment status as working, compared to 33.6 percent and 8.2 percent of older mothers. On the other hand, half of all of the oldest group of mothers is a widow.

However, we also find basic demographic differences between the groups beyond age. Our sample is 77 percent white, and just less than half have any college experience, at 42.3 percent. But working-age mothers have higher educational attainment than retiring or retired mothers, at 45.3 percent with some college attendance, compared to 25.6 percent and 16.6 percent, respectively. In addition, working-age mothers have ahighersharedivorced(at24 percent)compared tooldermothers(19.7 percent and 10.5 percent) and a lower share selfreporting to be a housewife (12.1 percent, compared to 14.2 and 17.2 percent). It could be that retired women prefer to claim status as a housewife rather than a retiree, but together these means indicate that older mothers in our sample are not simply older versions of younger mothers, but are a different cohort with different educational, marital, and work histories. This is important to keep in mind when interpreting the results.

The bottom half of Table 1 summarizes the dependent variables that we will use in our analysis. ${ }^{3}$ Respondents in the PSID are usually surveyed in the first few months of the year and asked for summary information about the prior calendar year; the dependent variables are the calendar-year totals. The first group of variables are cash transfers sent and received by the household. Heads and wives separately provide estimates of the amount of money they sent to a

\footnotetext{
${ }^{2}$ This is defined by Social Security, the early retirement age is 62 years old; all individuals must claim by age 70 .

${ }^{3}$ Appendix A, figures A2-A13 show the distribution of all of these variables by age.
} 
family member, and their relation to that member. ${ }^{4}$ They also each provide a total of how much they received from family, but do not specify who it was from. We combine transfers sent and received from heads and wives into a household summary measure. ${ }^{5}$ While they are younger, mothers' households are net senders of transfers. 8.5 percent of working-age mothers report sending a transfer to a child in a year and 6.9 percent received a transfer. Only 3.5 percent of older mothers report sending a transfer to a child but 5.2 percent report receiving a transfer. The table also shows the unconditional transfer amounts.

The second group of variables describes usual household food consumption, which combines the monetary value of food stamp benefits with the reported spending on food consumed at and away from home. It is the only consistent measure of consumption in the survey. Total household food consumption declines with age, from $\$ 8,060$ to $\$ 5,060$, though per capita food consumption (the household total divided by family size) rises and then falls, from $\$ 4,738$ for working-age mothers, to $\$ 5,361$ and then $\$ 4,430$ for the oldest mothers. These variations could reflect economies of scale in larger households, changes in preferences toward or ability to afford more expensive food, as well as reductions in food consumption overall.

The third group of variables summarizes sources of income, including the total weeks worked in the year, the share of mothers whose household has any Social Security income, ${ }^{6}$ and the share who receive Supplemental Nutrition Assistance. As expected, working-age mothers work more weeks during the year, have lower shares of Social Security receipt and higher SNAP receipt.

Finally, the PSID added in 1999 regular measures of wealth, including individual

\footnotetext{
${ }^{4}$ This total excludes legal transfers, such as alimony and child support.

${ }^{5}$ For parsimony, we refer to a year in which a positive transfer amount was reported as a single transfer, though it could be multiple disbursements within the year.

${ }^{6}$ The PSID varies in its collection of information regarding Social Security income, asking about individual receipt in some years and family receipt in others. We use household-level summaries in all years for consistency, but that means we cannot identify the recipient within the household for most years of the survey.
} 
contributions to pensions or retirement savings accounts, the value of total family wealth and its components, including value of vehicles and value of IRAs. 12.2 percent of working-age mothers are contributing to a pension, and contribute an unconditional average of just less than 1 percent of their income, while comparatively few retired mothers are currently contributing. However, the course of retirement savings is visible in our sample. Younger mothers, still contributing to their IRA have lower IRA value of $\$ 47,000$, mothers around the time they retire have roughly $\$ 112,000$ in their IRAs, and retired mothers, who have likely drawn down on their savings, have $\$ 73,000$.

In summary, our sample straddles mothers of varying financial resources and flexibility, from younger mothers who are working and contributing to savings, older mothers who are on Social Security income and drawing down their savings, and the mothers who are transitioning between the two states.

\subsection{Unemployed Adult Children}

We define an unemployment spell as a calendar year in which the child was unemployed for at least one week. ${ }^{7}$ We further restrict unemployment spells not to be concurrent with the final year of schooling and to be proceeded by labor force participation in the previous year of at least 26 weeks of employment, in order to exclude spells associated with labor force entry or re-entry. Figure 1 shows the distribution of ages of unemployed adult children in our sample the year they experienced a non-entry unemployment spell and the distribution of the age of their mothers in that year. Unemployment peaks between the ages of 24 and 33, and then gradually declines among older workers; half of spells occur before age 30. For mothers, unemployment among children is centered around a peak at age 57, occurring as early as 40 and as late as age $85 .^{8}$

\footnotetext{
${ }^{7}$ We use the term spell for parsimony; it could in fact be multiple spells within the annual total.

${ }^{8}$ Appendix Figure A1 shows Figure 1 as a scatter plot of the age of mothers matched with the age of their unemployed adult child, which shows the same concentration between 20 and 30 among children
} 
The demographic characteristics of unemployed adult children matched to mothers in our sample, as well as characteristics of the spell, are summarized in Table 2 for all unemployed adult children, and grouped by the age of their mother. The average age of unemployed children is 32.2, with a nearly even split of men and women, though the child's average age increases with the age of the mothers, from 28.8 years old to 44.9. Similar to mother's age predicting the sources and scope of financial resources available to her, child's age is indicative of the needs and constraints of her household. For example, although marriage rates are similar for each set of unemployed children, the share with children of their own at home drops from 67.6 percent to 49.3 percent. In addition, 50.2 percent of unemployed children of working-age mothers have more education than their mother, but this increases to 63.1 percent for the oldest mothers. Hence, the relative position of mothers to children is different among the three groups.

We also examine events that are concurrent with the year of the child's unemployment spell that could also lead to financial assistance from parents. Self-reporting of disability joint with an unemployment spell is rare, with less than one percent of spells for children or workingage and retiring mothers, and 1.9 percent of spells for children of the oldest mothers. More common is the concurrent reporting of a new child in the unemployed household in the year of a spell, averaging 11.1 percent of spells for children of working-age mothers and 4.1 percent for children of oldest mothers. Also more common is for a child's unemployment to coincide with that child's divorce, averaging 10.1 percent of spells fairly consistent across the age groups. Due to the timing of the survey window, we can only identify that both events (unemployment and birth/divorce) occurred within the same calendar year and not which preceded the other, and it could be the case that the unemployment spell is prompted by the birth of a new child or divorce.

To understand more about the nature of the child's unemployment, we also examine the characteristics of the spell itself. Recall that our definition of unemployment requires that the 
spell year must be preceded by prior labor force participation, which is combined employment and unemployment totaling at least 26 weeks, so as to avoid spells that are labor market entry or school exit. We separate here whether that was part-year work (26-39 weeks employed) or fullyear work (40 or more weeks employed). The majority of unemployed children were employed more than 40 weeks the year prior to the spell (59.2 percent), which rises with the age of the worker to 64.3 percent for the oldest group. Once unemployed, the majority experience a spell of less than 26 weeks, the maximum number of weeks that unemployment insurance benefits are available. The proportion with shorter unemployment spells falls with age, from 76.1 percent of spells for younger to 66.1 percent for older. We are also able to observe labor force participation in the year following the spell. For all age groups, labor force attachment is high; 75.8 percent remain in the labor force in the year following a spell of unemployment. Hence, the majority of unemployed children in our sample are full-time, full-year workers who experience a short spell and then return to work in the following year. Unfortunately, due to survey design, many spells have no information about the reason for unemployment.

In summary, unemployed children have similar demographic variation as their mothers do, but their spells and labor force attachment is comparatively much more uniform.

\section{Empirical Model}

Our estimation strategy can be generalized in the following way. Given parent $\mathrm{p}$, in year $\mathrm{t}$, with child c:

$$
Y_{p t}=X_{p t} \beta_{p}+X_{c t} \beta_{c}+\gamma U C_{c t}+\theta_{p}+\mu_{t}+E_{p t}
$$

Where $Y_{p t}$ is the parents' outcome of interest, $X_{p t}$ is a set of parental covariates, $X_{c t}$ is a set of child covariates, $\theta_{p}$ is individual (parent) fixed-effect and $\mu_{t}$ is calendar year fixed-effect. Our model relies on within-person variation in $Y_{p t}$, identified from $U C_{c t}$, a dummy variable equal to one if the mother had an adult child who was unemployed for at least one week in 
year $t$. We test four groups of dependent variables: transfers, income, consumption, and saving. We operationalize these outcomes in a number of ways. For transfers we measure both the real dollar amount and a dummy for transfers sent to children or received from family by the mother's household; income is measured through the mother's labor supply, as well as the mother's household labor supply, and program income from Social Security and Supplemental Nutrition Assistance; consumption is measured by usual house- hold food consumption; and savings includes the mother's individual contributions to retirement savings and household IRA and vehicle wealth.

Given the use of individual fixed effect for the mother, we include in $X p t$ changes in mothers' observed marital status, self-reported disability, unemployment rate in her state, retirement status, work status, age fixed effects, and a dummy variable for any unemployment in the mother's household, experienced by either herself or by her partner or spouse. $X_{C t}$ is a vector of child characteristics that may be related to parental assistance outside of unemployment, specifically, dummies for if a child got married, divorced, had a child, or became disabled.

The identifying assumption of equation (1) is that $U C_{c t}$ is exogenous. That is a strong assumption, for two reasons. First, the availability of assistance from parents could prompt unemployment among children. We cannot account for this directly, but we can measure the extent to which behavioral changes in parents are induced before or after the spell. The model in equation (1) can be expanded to $U C_{c t}^{j}$,

$$
Y_{p t}=X_{p t}^{\prime} \beta_{p}+X_{c t}^{\prime} \beta_{c}+\sum_{j=1}^{J} \gamma_{j} U C_{c t}^{j}+\theta_{p}+\varepsilon_{p t}
$$

Where $j$ are the years before or after the spell in $j=0$ and $j \in[-3,3]$. Hence, the estimates of $\gamma_{j}$ capture the time path of the dependent variable in the years preceding and following an adult child's reported unemployment. This method of identification — event study with fixed effects — is similar to studies of wages before and after displacement(Stevens, 1997), as well 
as outcomes before and after hospitalization (Dobkin et al., 2016).

The second issue with the exogeneity assumption of $U C_{c t}$ is that parents likely have a belief, or prediction, of their child's unemployment probability. Parental-fixed effects control for any time-invariant aspect of this, but not for updated or evolving opinions. To the extent that this is occurring, then the interpretation of $\gamma$ changes, ranging from the response to a fully exogenous income shock to the child's household, to a perfectly anticipated income reduction to the child's household. Our model cannot determine how random a child's spell is to parents, and where in the range of potential interpretation $\gamma$ lies. However, whatever behavioral changes are induced among parents are still informative to understanding the cost of risk bearing.

\section{Results}

\subsection{Financial Assistance}

We first estimate equation (1) when $Y_{p t}$ are measures of financial assistance from mother to child. Prior literature has established that parents send financial assistance to their children in certain instances, including unemployment (Cox and Way, 2011; Edwards, 2017); we want to confirm that finding within our sample before examining other outcomes. We use two measures of transfers in $Y_{p t}$, presented in Table 3: The first as a dummy variable for any transfer sending, and the second as the real dollar amount of the transfer. ${ }^{9}$ The estimated $\gamma$ when transfers are a dummy variable in column 1 is $0.018(.004)$, or a 1.8 percentage-point increase off of a mean rate of 7.2 percent, a 25 percent increase in the probability of sending a transfer.

In column 2, we regress a vector $\mathbf{U} \mathbf{C}_{c t}$ where single dummy $U_{c t}$ is divided into three dummies based on mother's age when the child was unemployed. Specifically,

$$
Y_{p t}=X_{p t}^{\prime} \beta+X_{c t}^{\prime} \beta_{c}+\gamma_{1} U C_{c t}^{A 1}+\gamma_{2} U C_{c t}^{A 2}+\gamma_{3} U C_{c t}^{A 3}+\theta_{p}+\varepsilon_{p t}
$$

\footnotetext{
${ }^{9}$ Means of transfer sending and conditional transfer amount can be found in figures A2 and A3 of Appendix A.
} 
Where A1 is working age mothers, A2 is retirement window mothers, and A3 is retired mothers. The coefficient estimate is largest for mothers younger than 62, at $0.021(0.005)$, and declines for mothers ages 62 to 70 to $0.013(0.006)$, and further for mothers older than 70 to $0.006(0.008)$, which is not precisely estimated. Columns 3 and 4 show the similar estimates when Ypt is the dollar amount of the transfer sent; the results are comparable. There are large and precisely estimated coefficients for the total population of mothers, but estimates are larger for younger mothers relative to the oldest mothers. ${ }^{10}$

In Figure 2, we show the coefficient estimates for the parental transfer dependent variable when $\mathbf{U C}_{\mathrm{ct}}$ is the time-path before and after unemployment, the event study from equation (2). The markers are the point estimate of the regression coefficient and the bars are the standard errors; three years before are omitted. The transfer amount dependent variable, in figure 2 , shows a spike in the year of the spell, but the years outside the spell are not positive. Hence, there is little evidence that parents pre-finance spells or may continue to assist even after the spell is completed. $^{11}$

To further understand the financial flows between parents and children, we also examined whether unemployed children affected the probability of mothers receiving a transfer, rather than sending one. There was no significantly estimated effect (neither decrease or increase) for mothers of any age, for either measure of transfers. Our finding that parents are more likely to send a transfer to a child in the year they experience an unemployment spell corroborates similar results in previous studies (Cox and Way, 2011; McGarry, 2016; Edwards, 2017). One shortcoming of the results presented here is that they are likely not exhaustive of the total financial assistance sent from parents to children since we do not have measures of residential transfers (cohabiting), and as a consequence of available data, also do not include any in-kind

\footnotetext{
${ }^{10}$ The findings are similar if we use a Tobit regression without mother-fixed effects and more expansive $X_{p t}$ vector.

${ }^{11}$ The dummy transfer amount event study looks similar, excluded for parsimony.
} 
transfers. Regardless, they do establish that parents financially assist unemployed children, and we can turn to our research question, how this assistance is financed and if we can observe any change in behavior.

\subsection{Effect on Consumption}

Consumption is the most basic measure of welfare, and it is also an adjustment that all individuals, even those on a fixed income, can make in response to an income shock. Most accounting of consumption and household expenditures are not captured in the PSID and, in the years when more consumption measures are available, they are not measured frequently or consistently, save annual household spending on food. ${ }^{12}$ Although this is the only measures part of total household consumption, food consumption has been used in prior studies to proxy for overall consumption, notably in Gruber (1997), a study of the consumption smoothing effects of unemployment insurance.

In Table 4, we estimate equation (1) when the dependent variable $Y_{p t}$ is log annual food consumption (columns 1 and 2) and annual food consumption in real 2013 dollars (columns 3 and 4). For both forms of the dependent variable, the main effect is negative and precisely estimated, -.041 (.008) log, and $-\$ 255.959$ (49.438) in dollars. By age, the precision of the estimate diverges by the log or dollar variable, the former suggesting that the largest drop is for the oldest mother, and the latter suggesting it is for working age mothers. Together, the coefficients indicate mothers of all ages significantly reduce their food consumption in the year of a child's unemployment spell.

Figure 3 shows the event study coefficients for the log dependent variable. Consumption declines in the year of the spell; the decline persists for the two years following before regaining its former level. A sustained drop in consumption in mothers' households after the spell has ended could reflect either a continued need for assistance or a change in expectations

\footnotetext{
${ }^{12}$ Summaries of usual household food consumption by age can be found in figure A4 of Appendix A.
} 
about future need. Our estimates cannot comment further on which is the case. Regardless, a drop in consumption among a parent's household associated with an adult child's unemployment is a major finding, contributing to our understanding of how risk and income shocks are absorbed across family networks, to the extent that consumption shocks are shared across households.

\subsection{Effect on Income Behavior}

There are two measures of income behavior in the PSID that we can exam- ine through the empirical framework in equation (1). Labor supply, as measured through the weeks worked per yearand hours worked perweek; and program participation in Social Security and Supplemental Nutrition Assistance Program. Asset and dividends, such as from the sale of a car, we consider dis-saving, rather than income, and discuss in that section. Given that labor supply is very low among mothers who are eligible for retirement, we present our results for younger mothers only. Similarly, given that Social Security receipt is so low among mothers ineligible for retirement (and nearly universal for households older than 70), we present our results for retiring mothers (age 62 to 70 only). ${ }^{13}$

We are interested in both the extensive and intensive margin of labor supply, whether nonworking mothers return to work or currently working mothers increase their hours or weeks. As noted previously, an average of 70.3 percent of mothers are working in any given year. Conditional on currently working, roughly 75 percent work full-time (35 hours or more a week), full-year (40 or more weeks in a year). ${ }^{14}$

The coefficient estimates from equation (1) when $Y_{p t}$ is mothers' total weeks employed in a year are presented in Table 6 for mothers less than 62 years old. In columns 1 and 2, we test the individual reported weeks employed by the mother. The coefficient estimate of $\gamma$ of child's unemployment is a 0.592 increase in the number of weeks worked, on a base mean of 35.3

\footnotetext{
${ }^{13}$ Results for other age groups available upon request; none were significant.

${ }^{14}$ Detailed graphs of lifetime and current period labor supply of mothers can be found in figure A5A7 of Appendix A.
} 
weeks. This is a small though precisely estimated increase in labor supply in the year a child experiences unemployment.

In column 2, we divide mothers into four groups by their average observed labor supply: ${ }^{15}$ zero, low (0-20 weeks), mid (20-40 weeks), and high (40 or more). The increase in weeks of work is driven by mothers who have high life-time labor supply, at 0.575 , with no detectable increase for less labor force attached mothers. Hence, we do not find that nonworking mothers increase their labor supply in the year of a child's spell, but working mothers do. ${ }^{16}$

It could be the case, however, that nonworking mothers have partners who can adjust their labor supply; it may be less difficult or costly for current workers to adjust. For this reason, in columns 3 and 4 we examine the total household week worked, which includes the labor supply of the mother's spouse, among women who are partnered. Again, the coefficient is positive and significant, a 1.011 increase in the total weeks worked by the head and spouse in the year of an unemployment spell of the mother's child. Column 4 shows that, similar to the mother's individual labor supply, increases in the household's labor supply is driven by more labor force attached mothers' households, increasing 1.382 weeks for households of mothers with 20-40 week lifetime average labor supply and 1.017 for households of mothers with more than 40 weeks lifetime average labor supply.

Hence, we find that concurrent increases in labor supply among the parents of unemployed adult children is occurring on the intensive margin for mothers or their households at or near full-time. In Figure 4, we present the coefficients from the event study in equation (2) for the total weeks employed of mothers younger than 62 years old to measure if the increase in labor supply persists. There is no increase in weeks employed in the years leading up to a child's

\footnotetext{
${ }^{15}$ We only included in the average years observed between ages 25 to 60 , two years prior to the analysis period.

${ }^{16} \mathrm{We}$ further tested a dummy variable equal to one if there was positive labor supply, a more direct way to measure if mothers were returning to work. There was no evidence of a positive increase, at any age. We separately examined hours per week, rather than weeks per year, of employment, as not all workers can adjust on both margins. We did not find a significant change.
} 
unemployment spell, a large increase in the year of the spell, and noisy estimates of the years following, though they weakly suggest that weeks worked remains high relative to the years prior to the child's spell.

The second income behavior we examine is from program participation in SNAP or Social Security. The margins by which mothers and their households can alter their behavior in order to increase income via either program is very small, given the eligibility constraints and observed claiming behavior. ${ }^{17}$ SNAP has income-based eligibility requirements. To increase SNAP in the year of a child's unemployment, a mother would have to have been eligible but not claiming household benefits until the year of the child's spell, a very small margin, especially since SNAP receipt in our sample is low, at 7.0 percent. On the other hand, individuals may not claim Social Security retirement benefits until age 62, the Early Retirement Age (ERA), and have no financial incentives to claim after age 70 . By age $65,86.4$ percent of mothers in our sample report Social Security income. We did not find significant effects on program participation for either program. $^{18}$

\subsection{Effect on Savings}

The last set of behaviors that we examine is savings. Savings variables were measured in each wave beginning in 1999, and take two forms. First, there is a measure of retirement savings contributions; the PSID asks what percent of income is put toward a pension. Second, there are measures of asset values as components of total wealth.

Table 6 shows the coefficient estimates when $Y_{p t}$ is the unconditional percentage of income contributed to retirement savings (columns 1 and 2) and a dummy for any contribution to

\footnotetext{
${ }^{17}$ Program receipt by age can be found in figures A8 and A9 of Appendix A.

${ }^{18}$ We found marginal support for effects on Social Security income, but only among women whose child became unemployed when the mother was age 66 to 69 , was partnered, and had a high lifetime labor supply. Given that this is a very small group among a much reduced sample, we do not present them here out of concern than they are spurious.
} 
a pension (columns 3 and 4). ${ }^{19}$ For these regressions, we add a five-knot linear spline controlling for total household wealth. We evaluate the effect of savings rates on retirement savings contributions for mothers younger than age 62 only. We find, in column 1, there is a decrease in savings rates of -0.136 for working age mothers, off of a mean contribution rate of .663 , a relatively large decline of roughly 20 percent. Yet, given the much smaller sample size in the truncated time period, the remaining results, which examine contribution rates by lifetime labor supply of the mother and a dummy for any contribution, though negative, are imprecisely estimated. Figure 5 we examine the time path of savings among working age mothers 20 in the accompanying event study. The results follow the pattern of the previous dependent variables: a large and precise decline in the year of the spell, and no consistent effect in the years before or following the spell.

Finally, we examine asset values of mothers' households in the year of child's unemployment spell. Although the PSID has seven asset measures, we present results for one: vehicle value. Few mothers have any farm/business value, real estate outside of a primary home, stocks, or other assets. A larger share have an IRA, but the the distribution of IRA value, even conditional on having an IRA, is highly skewed: The mean IRA value is $\$ 69,000$, but the standard deviation is $\$ 274,000$. Although many mothers have home equity, it is not a reasonably liquid asset, especially relative to a vehicle. ${ }^{21}$

The coefficient estimates for the change in vehicle value are presented in the final two columns of Table 6 . Unlike the previous columns, we examine vehicle value for all mothers regardless of age. The mean effect is negative and precise in column 5, at -252.01 ; in the year of a child's unemployment spell, mothers will see an average decline of $\$ 252$ in vehicle wealth. Column 6, which interact child's unemployment with mother's age, shows the decline in vehicle

\footnotetext{
${ }^{19}$ Distributions of pension contribution by age can be found in figure A9 and A10 in Appendix A.

${ }^{20}$ The years before and after the spell are in increments of two because the survey became biennial.

${ }^{21}$ For an example of the skew of distribution, the distribution of IRA and vehicle value can be found in figures A10 and A11 of Appendix A.
} 
value is driven by the oldest mothers, at -910.941. A decline in vehicle value does not necessarily indicate that a car was sold; it could also be the case that a decline in vehicle value captures that parents have transferred a car to their children. Regardless, we find a reduction in the value of a liquid asset among older mothers, who are relatively budget constrained. Figure 6 presents graphically the estimates of the event study from equation (2); the time path of vehicle wealth is to decline in year of the spell and not regain previous values until multiple years after the spell.

\section{Robustness}

In the previous section, we presented estimates of the changes in a mother's transfers, consumption, income, and savings in the year an adult child was unemployed, measured through a variety of variables. The simplest test of internal validity of our findings is to examine if the estimates are compatible across categories. That is, assuming a simple budget constraint:

$$
0=I_{t}+A_{t}-C_{t}-S_{t}-T_{t}
$$

Where in a given period income and assets net of consumption, savings, and transfers is zero, any change to one component is equaled by a change in another component, so that the remainder is still zero.

This equation does not hold in our findings. When looking at the mean effect for mothers of all ages, and including only precise estimates from Tables 3-6, we find transfers to children increase by $\$ 76$, consumption on food decreases by $\$ 255$, and vehicle value by $\$ 252$. The gap is larger for working-age moms, who transfer $\$ 65$ but drop food consumption by $\$ 260$, work three more days that year, and reduce retirement savings by 20 percent. Clearly, point estimates should be interpreted with caution, and greater emphasis placed on the direction, rather than size of the estimate. Yet aside from estimate precision, the increase in income and declines in consumption, 
savings, and assets are not similar in size to the transfers given to children in our analysis; this has (at least) two possible explanations.

First, our categories are only partially measured. For example, using reported estimates of cash transfers sent to children in a year likely misses most forms of in-kind assistance, including the direct purchase of goods and services or nonmonetary gifts, such as buying food or paying rent for a child, co-financing arrangements, such as giving a child access to a credit card that the parent pays for, and the provision of services, such child care or transportation.22 It is possible that parents report the cash equivalent of that assistance in response to the survey question about sending money to children, but we have no means for assuming whether they do or do not; however, given the regular under-reporting of transfers (Meyer, Mok, and Sullivan, 2009), it is unlikely that all transfers are fully captured. Partial measurements across categories likely explain why our simple budget constraint test did not equal out. However, we cannot say more about this within our data.

A second, and not exclusive, explanation is that parental adjustments in behavior to income, consumption, and savings do not only account for the financial exigencies of sending transfers in one period, but also the updated expectations of future need, or increased risk going forward. The estimates from the event study in equation (2) that are presented graphically in figures 2-6 show to what extent the single-period change in behavior persists in the years following an unemployment spell. Although transfer coefficient estimates return to zero in the year immediately following a child's unemployment spell, food consumption, weeks employed, savings rates, and vehicle value all have post-spell changes in the one to two following years. The difference in post-spell behavior may be interpreted as risk-adjusting behavior.

\footnotetext{
22 As noted previously, our study excludes co-residence as a transfer and co-resident unemployed children.
} 


\section{Discussion}

In this paper, we examine the transfer, income, consumption, and savings behavior of mothers in the year that an adult child experienced an unemployment spell. While each component had results that varied in degree by age of the mother, the broad conclusion is that a child's unemployment spell significantly alters the mother's behavior. Three simple but important conclusions follow from this research. First, younger mothers (younger than 70) transfer money to their children when the child is unemployed, and older mothers transfer assets (most likely a vehicle). Second, the youngest mothers (younger than 62) who have the most margins to change their behavior change on nearly every dimension: They reduce their food consumption, increase their labor supply, and reduce their pension savings. Finally, the behavioral changes are larger than the monetary value of transfers - implying that either a) there are other mechanisms for transferring income to unemployed children that are not captured by cash transfers, or b) the behavioral response is in anticipation of changes in expectation about their child's career prospects or changes in the probability of future employment disruptions.

Overall, the effect of child unemployment on mothers' labor market, consumption and savings behavior is large and is likely larger than we describe since we exclude adult children cohabiting with parents. Despite the estimated effects on mothers, however, we do not undertake a welfare analysis. We simply assume that changes in behavior are offset by the utility gained by having children with higher welfare. It is an open question whether a sense of familial obligation, altruism, or an exchange relationship is the underlying motivation for transfers and subsequent changes in parental behavior. Regardless of motivation, it is clear that mothers are likely to help their children, and they are likely to make changes to their consumption, income, or savings behavior in order to, or as they, do so.

Welfare of the mother does not translate into the optimal distribution of risk. Parents' risk 
sharing with their children could be suboptimal in the manner our results suggest, that parents are bearing, and paying for, the risk to their children as they enter a time period associated with higher risk to themselves (the risk of retirement insecurity). However, it could be suboptimal in numerous other ways. Distributionally, family risk sharing caps the insurance of one family member by the wealth of another, or conversely, the wealth of one family member by the risk of another. Unemployment risk is not distributed randomly in either the income or wealth distributions, meaning that risk may concentrate among those families with less means to face it. Macroeconomically, poorly insured individuals may take longer to recover from an income shock during recessions. Our paper cannot comment directly on the optimal distribution of risk, but makes the novel contribution toward estimating the cost of risk sharing among one population, which motivates further research on risk sharing more generally. 


\section{References}

Bianchi, Suzanne, V. Joseph Hotz, Kathleen McGarry, and Judith Seltzer. 2010.

"Intergenerational Ties: Alternative Theories, Empirical Findings and Trends, and Remaining Challenges." Intergenerational Caregiving, ed. Alan Booth, Ann Crouter, Suzanne Bianchi and Judith Seltzer. Urban Institute.

Cox, Donald, and Megan Way.2011. "Intergenerational Transfers and the Great Recession.” Technical report, Boston College Working Paper.

Cullen, Julie, and Jonathan Gruber. 2000. “Does Unemployment Insurance Crowd out Spousal Labor Supply?” Journal of Labor Economics, 18(3): 546-572.

Dobkin, Carlos, Amy Finkelstein, Raymond Kluender, and Matthew J Notowidigdo. 2016. "The Economic Consequences of Hospital Admissions.” (22288).

Edwards, Kathryn Anne. 2017. "Who Helps the Unemployed? Workers' Receipt of Private and Public Transfers." RAND Labor and Population Working Paper Series.

Gruber, Jonathan. 1997. “The Consumption Smoothing Benefits of Unemploy- ment Insurance." The American Economic Review, 87(1): 192-205.

Kaplan, Greg. 2012. "Moving Back Home: Insurance against Labor Market Risk.” Journal of PoliticalEconomy, 120(3): 446-512.

McGarry, Kathleen. 2016. "Dynamic Aspects of Family Transfers.” Journal of Public Economics, 137: 1-13.

Meyer, Bruce, Wallace K.C. Mok, and James Sullivan. 2009. “The Under- Reporting of Transfers in Household Surveys: Its Nature and Consequences.” NBER Working Paper Series, (15181).

Stevens, Ann Huff. 1997. "Persistent Effects of Job displacement: The Importance of Multiple Job Losses." Journal of Labor Economics, 165-188.

Wiemers, Emily E. 2014. "The Effect of Unemployment on Household Composi- tion and Doubling Up.” Demography, 51(6): 2155-2178. 
Figures 


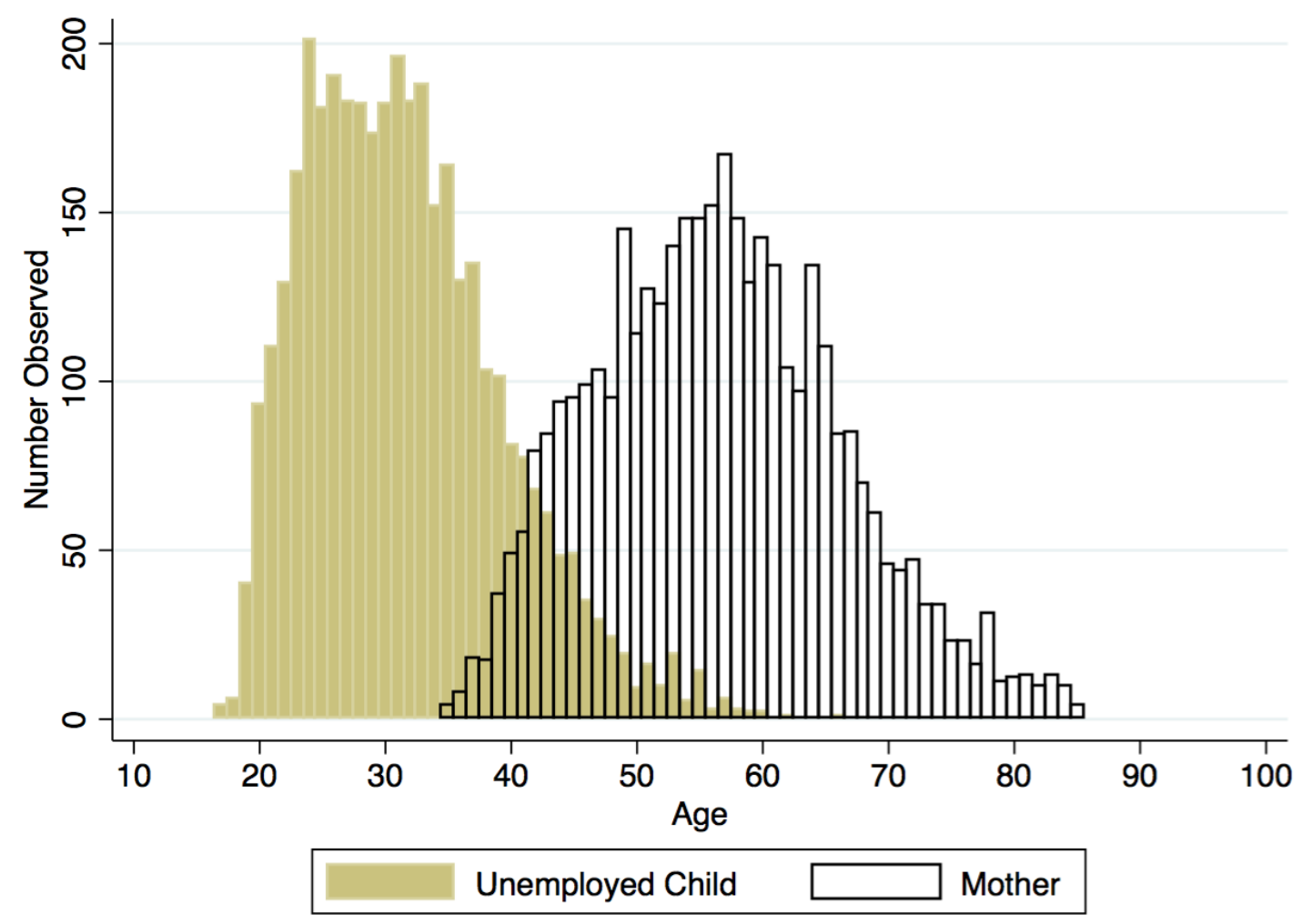

Figure 1: Age of Unemployed Heads/Spouses of Households and Matched Mothers, PSID, 1985-2013 


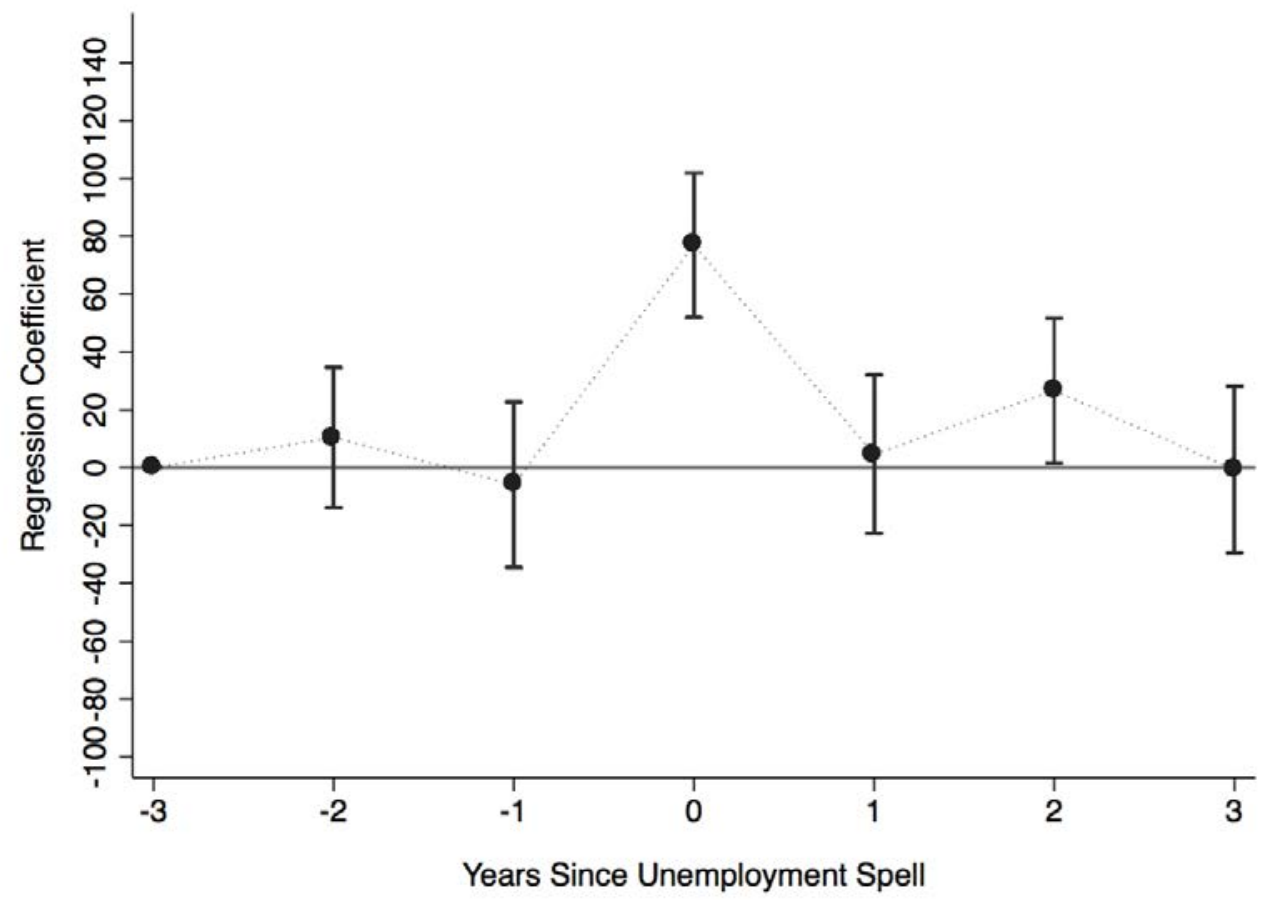

Figure 2: Coefficient Estimates, Regression of Dummy for Transfer Sent to Child on Child's Unemployment 


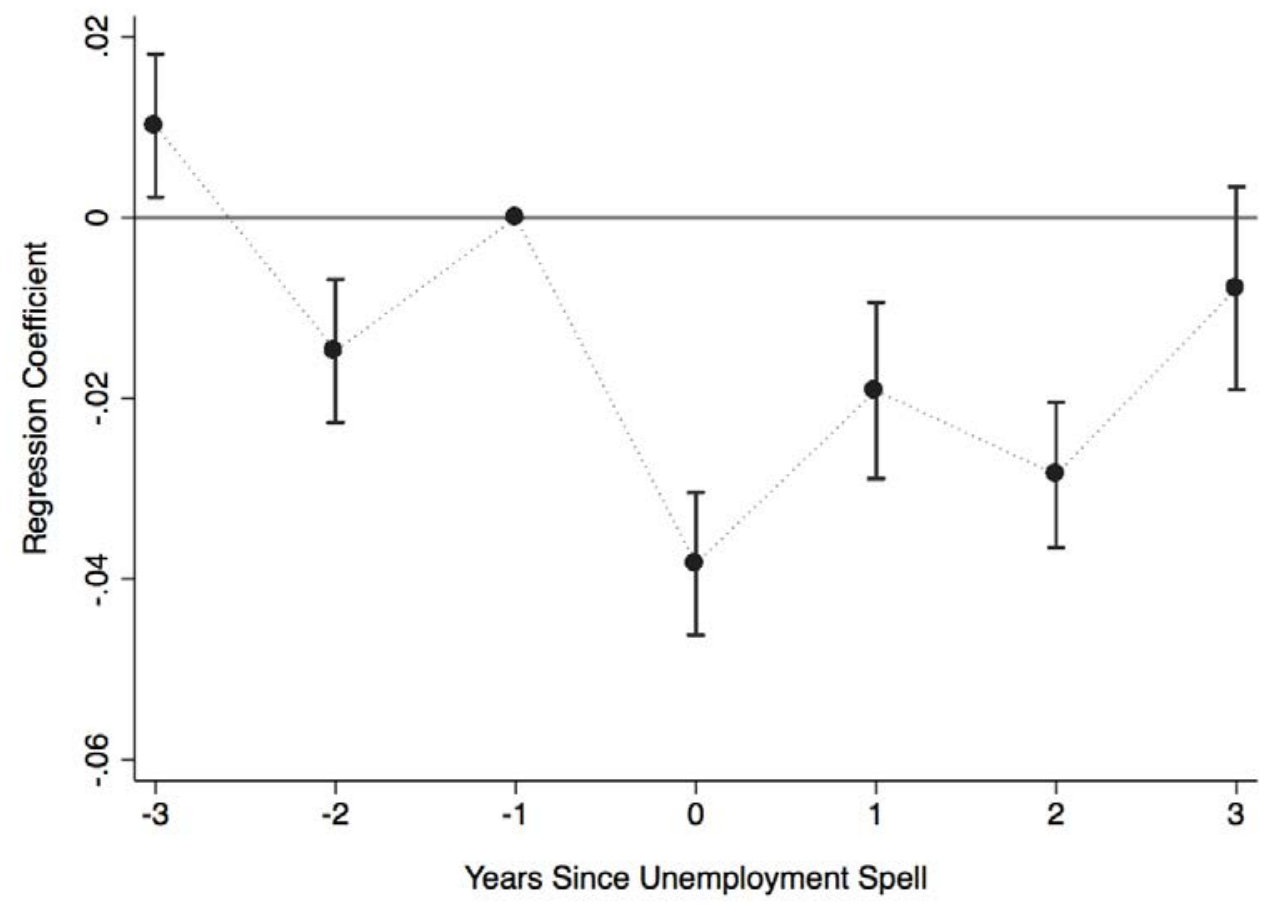

Figure 3: Coefficient Estimates, Regression of Log Household Food Consumption on Child's Unemployment 


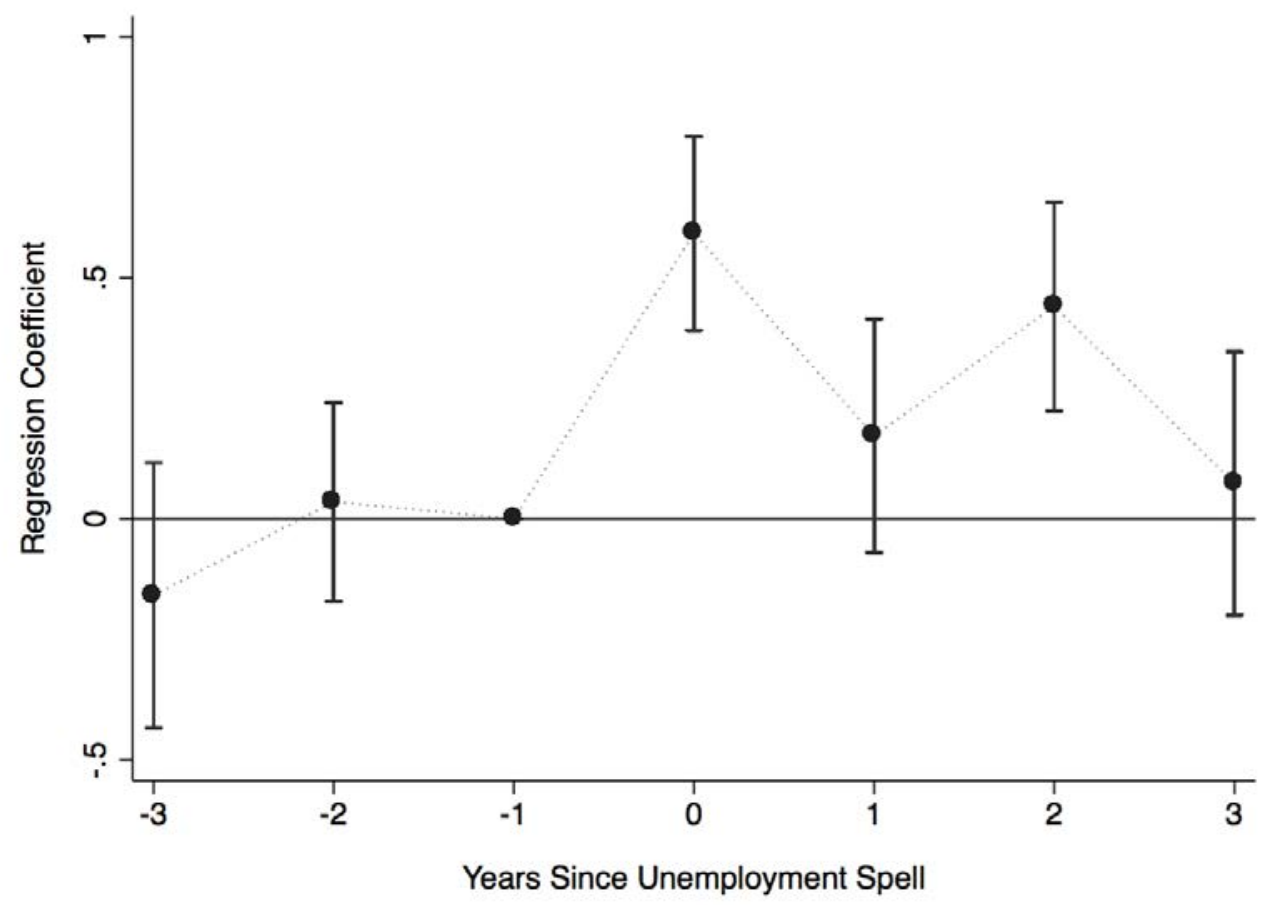

Figure 4: Coefficient Estimates, Regression Mother's Annual Weeks Employed on Child's Unemployment, Mothers Under Age 62 


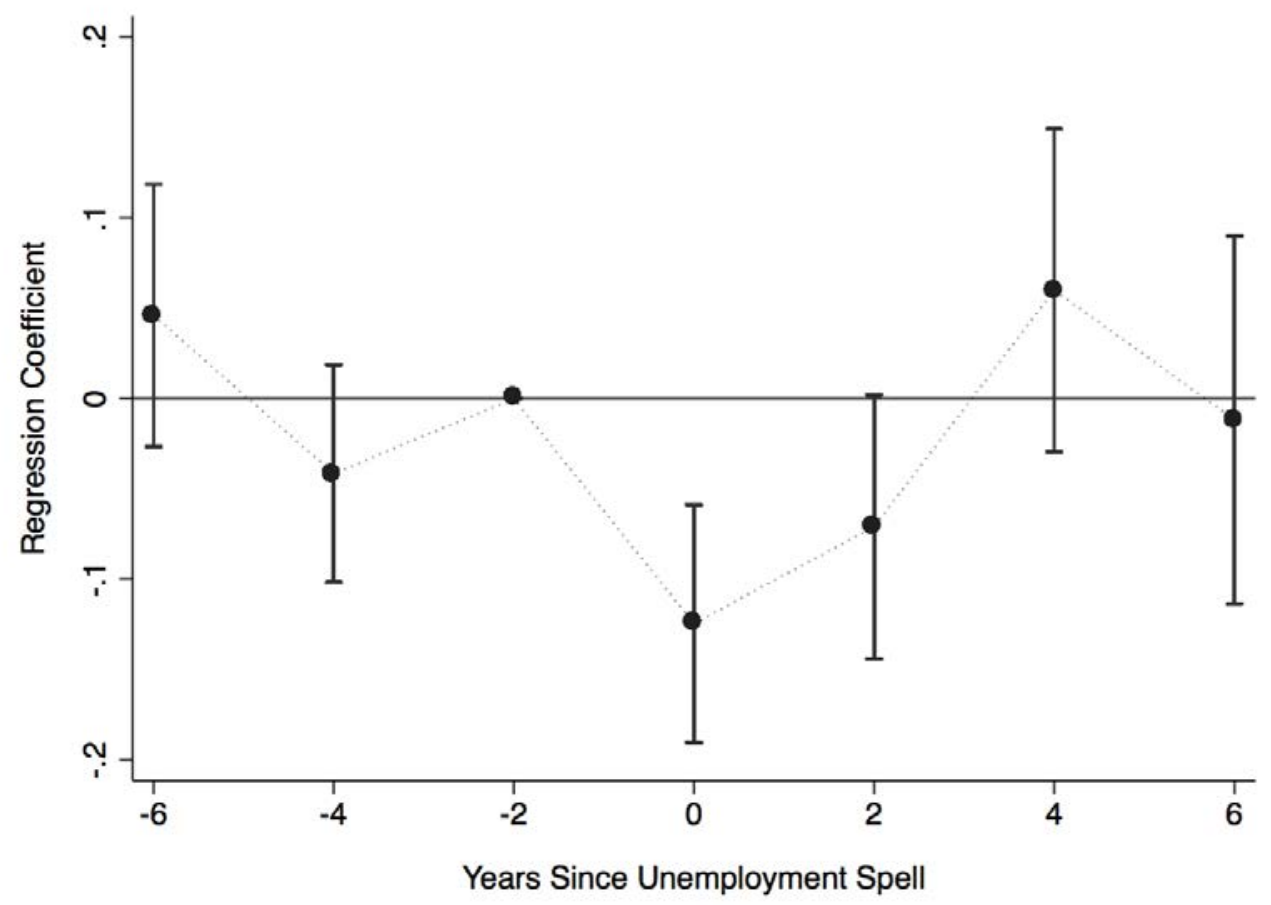

Figure 5: Coefficient Estimates, Regression of Mother's Average Pension Contribution Share on Child's Unemployment, Mothers Under Age 62 


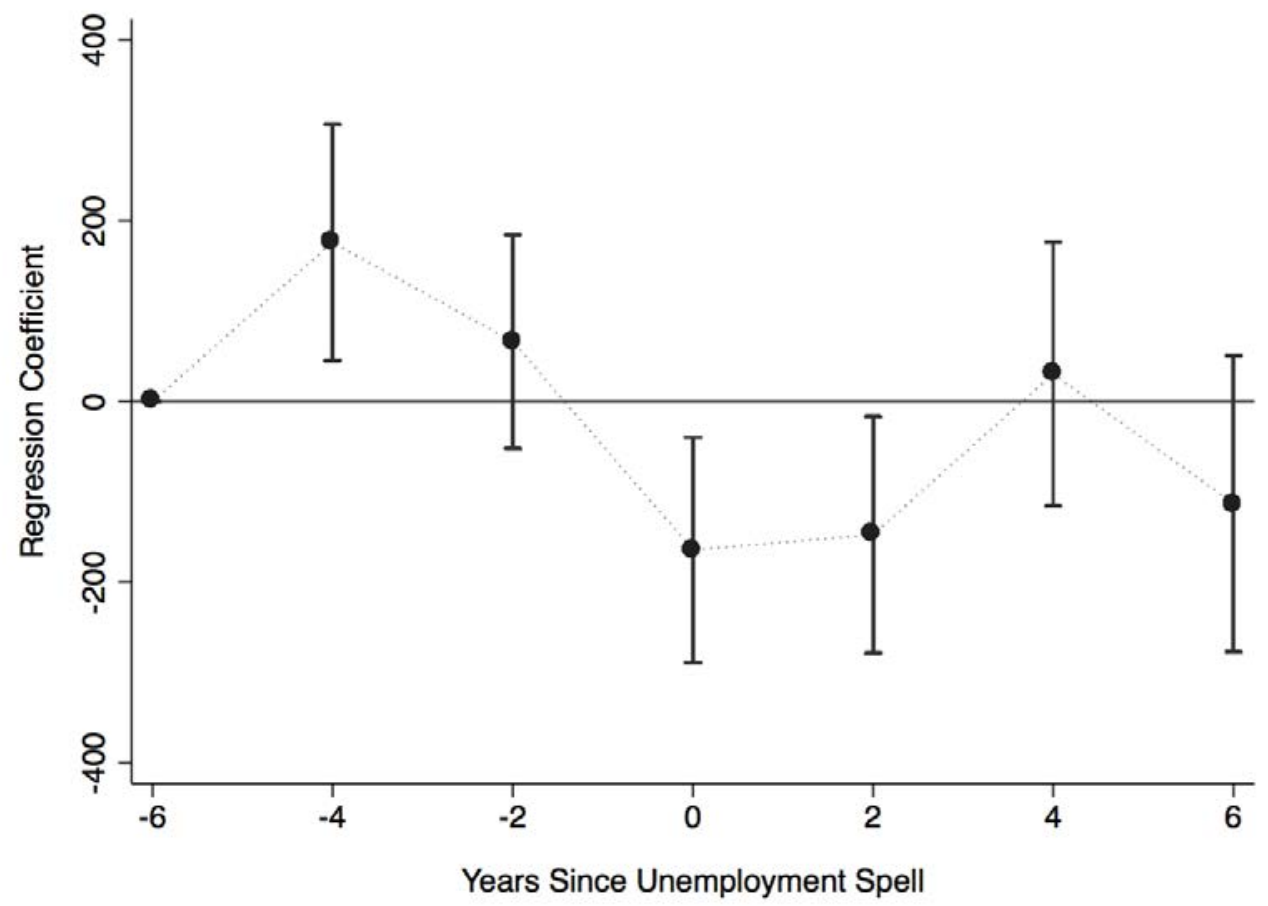

Figure 6: Coefficient Estimates, Regression of Mother's Vehicle Value on Child's Unemployment 
Tables 
Table 1: Summary of Mothers, by Age

\begin{tabular}{|c|c|c|c|c|}
\hline & $\begin{array}{l}\text { All } \\
\mathrm{N}=38004\end{array}$ & $\begin{array}{c}\text { Moms } \\
\text { Age } \\
<62\end{array}$ & $\begin{array}{l}\text { Moms } \\
\text { Age 62- } \\
70\end{array}$ & $\begin{array}{c}\text { Moms } \\
\text { Age } \\
>70\end{array}$ \\
\hline Age & 59.6 & 50.1 & 65.7 & 78.6 \\
\hline White & 0.772 & 0.762 & 0.851 & 0.804 \\
\hline Black & 0.127 & 0.133 & 0.073 & 0.136 \\
\hline High School or Less & 0.575 & 0.545 & 0.736 & 0.834 \\
\hline SomeCollege or More & 0.423 & 0.453 & 0.256 & 0.166 \\
\hline Married & 0.594 & 0.659 & 0.651 & 0.383 \\
\hline Divorced/Sep. & 0.201 & 0.240 & 0.197 & 0.105 \\
\hline Never Married & 0.040 & 0.062 & 0.012 & 0.007 \\
\hline Widow & 0.165 & 0.039 & 0.139 & 0.506 \\
\hline Disabled & 0.044 & 0.055 & 0.031 & 0.028 \\
\hline Housewife & 0.136 & 0.121 & 0.142 & 0.172 \\
\hline Working & 0.492 & 0.703 & 0.336 & 0.082 \\
\hline Sent Transfer to Kid & 0.070 & 0.085 & 0.068 & 0.035 \\
\hline Size of Transfer to Kid & $\$ 329$ & $\$ 373$ & $\$ 344$ & $\$ 206$ \\
\hline Received Transfer & 0.059 & 0.069 & 0.037 & 0.052 \\
\hline Size of Received Transfer & $\$ 187$ & $\$ 227$ & $\$ 101$ & $\$ 154$ \\
\hline Usual HH Food & $\$ 7196$ & $\$ 8060$ & $\$ 7124$ & $\$ 5060$ \\
\hline Familysize & 2.37 & 2.73 & 1.89 & 1.56 \\
\hline $\begin{array}{l}\text { Per Capita Food } \\
\text { Consumption }\end{array}$ & $\$ 4808$ & $\$ 4738$ & $\$ 5361$ & $\$ 4430$ \\
\hline Weeks Worked & 25.0 & 35.3 & 17.7 & 4.7 \\
\hline Receiving SSA Income & 0.458 & 0.138 & 0.840 & 0.966 \\
\hline ReceivingSNAP & 0.070 & 0.093 & 0.044 & 0.032 \\
\hline Contribute to a Pension & 0.079 & 0.122 & 0.034 & 0.005 \\
\hline Share of Income Cont. & 0.006 & 0.009 & 0.003 & 0.0003 \\
\hline Vehicle Value & $\$ 16851$ & $\$ 18320$ & $\$ 18972$ & $\$ 11437$ \\
\hline IRA Value & $\$ 65123$ & $\$ 47195$ & $\$ 111975$ & $\$ 73405$ \\
\hline
\end{tabular}

Source: Authors' Calculations of PSID data. 
Table 2: Summary of Adult Children in the Year of Unemployment, by Age of Mother

\begin{tabular}{|c|c|c|c|c|}
\hline & \multirow{3}{*}{$\begin{array}{l}\text { All } \\
\mathbf{N}=\mathbf{9 2 3 6}\end{array}$} & \multicolumn{3}{|c|}{ With Moms With Moms With Moms } \\
\hline & & Age & Age 62- & Age \\
\hline & & $<62$ & 70 & $>70$ \\
\hline Age & 32.2 & 28.8 & 37.1 & 44.9 \\
\hline Female & 0.509 & 0.517 & 0.488 & 0.501 \\
\hline With Minors & 0.645 & 0.676 & 0.617 & 0.493 \\
\hline Married & 0.464 & 0.450 & 0.494 & 0.488 \\
\hline Same State & 0.821 & 0.832 & 0.809 & 0.774 \\
\hline $\begin{array}{l}\text { Kid more educated that } \\
\text { mother }\end{array}$ & 0.541 & 0.502 & 0.620 & 0.631 \\
\hline Concurrent w/ disability & 0.006 & 0.004 & 0.010 & 0.019 \\
\hline Concurrent w/new child & 0.097 & 0.111 & 0.080 & 0.041 \\
\hline Concurrent w/ divorce & 0.101 & 0.104 & 0.100 & 0.085 \\
\hline Worked FT previously & 0.592 & 0.576 & 0.617 & 0.643 \\
\hline Unemp. Spell<26 Weeks & 0.728 & 0.741 & 0.716 & 0.661 \\
\hline Remain in LF after spell & 0.758 & 0.761 & 0.760 & 0.737 \\
\hline
\end{tabular}

Source: Authors' Calculations of PSID data. 
Table 3: Results from Regressions of Parental Transfer Behavior on Child Unemployment Indicator

\begin{tabular}{|c|c|c|c|c|}
\hline Dep. Var & $\begin{array}{r}\text { Sent a Tra } \\
\text { To a } \\
\text { [Du }\end{array}$ & $\begin{array}{l}\text { nsfer } \\
\text { Child } \\
\text { nmyl }\end{array}$ & $\begin{array}{r}\text { Sent a Trans } \\
\text { To a } \\
\text { [\$ Gr }\end{array}$ & $\begin{array}{l}\text { sfer } \\
\text { Child } \\
\text { oss] }\end{array}$ \\
\hline Sample & $\begin{array}{l}\text { All } \\
\text { (1) }\end{array}$ & $\begin{array}{l}\text { All } \\
\text { (2) }\end{array}$ & $\begin{array}{l}\text { All } \\
\text { (3) }\end{array}$ & $\begin{array}{l}\text { All } \\
\text { (4) }\end{array}$ \\
\hline Unemp Kid & $\begin{array}{l}0.018^{* * *} \\
0.004\end{array}$ & & $\begin{array}{l}76.781^{* *} \\
25.581\end{array}$ & \\
\hline Unemp Kid $*<62$ & & $\begin{array}{c}0.021 * * * \\
0.005\end{array}$ & & $\begin{array}{l}\text { 65.699* } \\
31.319\end{array}$ \\
\hline Unemp Kid *62-70 & & $\begin{array}{c}0.013^{*} \\
0.006\end{array}$ & & $\begin{array}{l}136.131 * * \\
44.907\end{array}$ \\
\hline Unemp Kid* $>70$ & & $\begin{array}{l}0.006 \\
0.008\end{array}$ & & $\begin{array}{c}38.95 \\
49.438\end{array}$ \\
\hline Unemp in Mom's & $\begin{array}{c}0.002 \\
0.01\end{array}$ & $\begin{array}{c}0.001 \\
0.01\end{array}$ & $\begin{array}{c}-56.351 \\
45.49\end{array}$ & $\begin{array}{l}-51.059 \\
46.502\end{array}$ \\
\hline Disabled (Child) & $\begin{array}{c}0.009 \\
0.01\end{array}$ & $\begin{array}{c}0.009 \\
0.01\end{array}$ & $\begin{array}{c}157.999 * * \\
49.03\end{array}$ & $\begin{array}{c}158.536^{* *} \\
48.876\end{array}$ \\
\hline Married (Child) & $\begin{array}{l}0.002 \\
0.005\end{array}$ & $\begin{array}{l}0.002 \\
0.005\end{array}$ & $\begin{array}{l}-0.234 \\
30.601\end{array}$ & $\begin{array}{c}0.263 \\
30.581\end{array}$ \\
\hline Divorced (Child) & $\begin{array}{c}0.013^{*} \\
0.006\end{array}$ & $\begin{array}{c}0.013^{*} \\
0.006\end{array}$ & $\begin{array}{l}61.686 \\
36.081\end{array}$ & $\begin{array}{l}61.749 \\
36.072\end{array}$ \\
\hline New child (Child) & $\begin{array}{l}0006 \\
0.004\end{array}$ & $\begin{array}{l}0.006 \\
0.004\end{array}$ & $\begin{array}{l}39.272 \\
29.596\end{array}$ & $\begin{array}{l}39.410 \\
29.604\end{array}$ \\
\hline Partnered(Mother) & $\begin{array}{l}0.053 \\
0.042\end{array}$ & $\begin{array}{l}0.054 \\
0.042\end{array}$ & $\begin{array}{l}130.452 \\
224.17\end{array}$ & $\begin{array}{l}130.677 \\
224.642\end{array}$ \\
\hline Divorced (Mother) & $\begin{array}{c}0.02 \\
0.042\end{array}$ & $\begin{array}{c}0.02 \\
0.042\end{array}$ & $\begin{array}{l}-84.771 \\
222.212\end{array}$ & $\begin{array}{l}-85.544 \\
222.681\end{array}$ \\
\hline Widow (Mother) & $\begin{array}{l}0.048 \\
0.042\end{array}$ & $\begin{array}{l}0.048 \\
0.042\end{array}$ & $\begin{array}{l}143.183 \\
221.942\end{array}$ & $\begin{array}{l}142.442 \\
222.455\end{array}$ \\
\hline Housewife(Mother) & $\begin{array}{r}-0.008 \\
0.007\end{array}$ & $\begin{array}{r}-0.008 \\
0.007\end{array}$ & $\begin{array}{l}-7.687 \\
54.827\end{array}$ & $\begin{array}{l}-8.868 \\
54.888\end{array}$ \\
\hline Retired (Mother) & $\begin{array}{c}-0.008 \\
0.008\end{array}$ & $\begin{array}{l}-0.009 \\
0.008\end{array}$ & $\begin{array}{l}-3.779 \\
54.948\end{array}$ & $\begin{array}{c}-5.298 \\
55.05\end{array}$ \\
\hline Disabled (Mother) & $\begin{array}{c}-0.008 \\
0.008\end{array}$ & $\begin{array}{l}-0.009 \\
0.008\end{array}$ & $\begin{array}{l}40.479 \\
49.235\end{array}$ & $\begin{array}{l}39.815 \\
49.294\end{array}$ \\
\hline Working (Mother) & $\begin{array}{c}0.016^{*} \\
0.007\end{array}$ & $\begin{array}{c}0.016^{*} \\
0.007\end{array}$ & $\begin{array}{l}97.620^{*} \\
43.955\end{array}$ & $\begin{array}{c}96.755^{*} \\
44.001\end{array}$ \\
\hline State UR (Mother) & $\begin{array}{l}0.001 \\
0.002\end{array}$ & $\begin{array}{l}0.001 \\
0.002\end{array}$ & $\begin{array}{l}-1.737 \\
13.465\end{array}$ & $\begin{array}{c}-1.746 \\
13.46\end{array}$ \\
\hline Year \& Age & $\mathrm{Y}$ & $\mathrm{Y}$ & $\mathrm{Y}$ & $Y$ \\
\hline FE & $\mathrm{Y}$ & $\mathrm{Y}$ & $\mathrm{Y}$ & $\mathrm{Y}$ \\
\hline $\begin{array}{l}\text { Individual } \\
\mathbf{N}\end{array}$ & $\begin{array}{l}7.2 \% \\
38004\end{array}$ & $\begin{array}{l}7.2 \% \\
38004\end{array}$ & $\begin{array}{l}\$ 336 \\
38004\end{array}$ & $\begin{array}{l}\$ 336 \\
38004\end{array}$ \\
\hline
\end{tabular}

Note: Standard errors listed. 
Table 4: Results from Regressions of Mother's Household Food Consump- tion on Child Unemployment Indicator

\begin{tabular}{|c|c|c|c|c|}
\hline \multirow{2}{*}{$\begin{array}{l}\text { Dep. Var } \\
\text { Sample }\end{array}$} & \multicolumn{2}{|c|}{ Log Annual Food } & \multicolumn{2}{|c|}{ \$ Annual Food } \\
\hline & $\begin{array}{l}\text { All } \\
\text { (1) }\end{array}$ & $\begin{array}{l}\text { All } \\
(2)\end{array}$ & $\begin{array}{l}\text { All } \\
\text { (3) }\end{array}$ & $\begin{array}{l}\text { All } \\
\text { (4) }\end{array}$ \\
\hline Unemp Kid & $\begin{array}{c}-0.041^{* * *} \\
0.008\end{array}$ & & $\begin{array}{c}-255.959 \text { *** } \\
49.438\end{array}$ & \\
\hline Unemp Kid $*<62$ & & $\begin{array}{c}-0.040^{* * * *} \\
0.009\end{array}$ & & $\begin{array}{c}-259.152^{* * * *} \\
59.348\end{array}$ \\
\hline Unemp Kid * 62- & & $\begin{array}{l}-0.027 \\
0.018\end{array}$ & & $\begin{array}{c}-250.088 * \\
101.756\end{array}$ \\
\hline Unemp Kid $*>70$ & & $\begin{array}{c}-0.074^{*} \\
0.032\end{array}$ & & $\begin{array}{c}-245.323 \\
130.048\end{array}$ \\
\hline$X_{\text {ct }}$ & $\mathrm{Y}$ & $\mathrm{Y}$ & $\mathrm{Y}$ & $\mathrm{Y}$ \\
\hline$X_{\text {pt }}$ & $\mathrm{Y}$ & $\mathrm{Y}$ & $\mathrm{Y}$ & $\mathrm{Y}$ \\
\hline Year \& Age FE & $Y$ & $\mathrm{Y}$ & $\mathrm{Y}$ & $\mathrm{Y}$ \\
\hline Individual & $\mathrm{Y}$ & $\mathrm{Y}$ & $\mathrm{Y}$ & $\mathrm{Y}$ \\
\hline FE Mean & 8.75 & 8.75 & $\$ 6904$ & $\$ 6904$ \\
\hline $\mathbf{N}$ & 38004 & 38004 & 38004 & 38004 \\
\hline
\end{tabular}

Note: Standard errors listed. The four regressions shown include but do not show estimates for child covariates (marital status, disability status, birth of a child) and mother's household covariates (presence of an unemployment member, marital status, disability status, employment status, and local unemployment rate). 
Table5: Resultsfrom Regressions of Mother'sLaborSupplyon Child Unemployment Indicator, Weeks Employed per Year

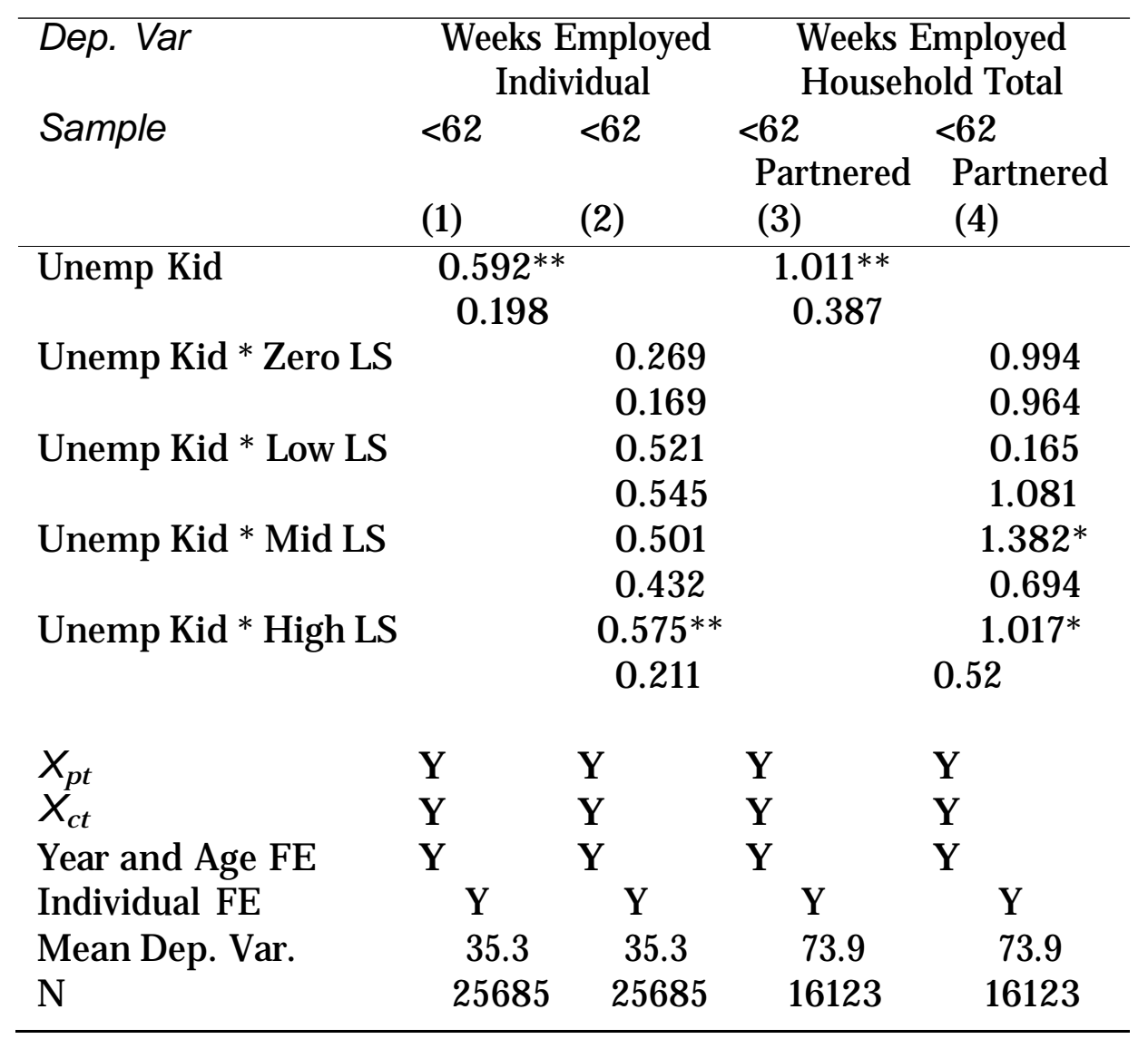

Standard errors listed. The four regressions showninclude but donot show estimates for child covariates (marital status, disability status, birth of a child) and mother's household covariates (presence of an unemployment member, marital status, disability status, employment status, and local unemployment rate). 
Table 6: Results from Regressions of Mother's Savings Behavior on Child Unemployment Indicator

\begin{tabular}{|c|c|c|c|c|c|c|}
\hline \multirow{3}{*}{$\begin{array}{l}\text { Dep. Var } \\
\text { Sample }\end{array}$} & \multicolumn{4}{|c|}{ Contributing to Pension } & \multirow{2}{*}{\multicolumn{2}{|c|}{$\begin{array}{c}\text { Asset Value } \\
\text { Vehicle Value }\end{array}$}} \\
\hline & \multicolumn{2}{|c|}{ Percent of Income } & \multicolumn{2}{|c|}{ Dummy for Cont. } & & \\
\hline & $\begin{array}{l}<62 \\
(1)\end{array}$ & $\begin{array}{l}<62 \\
(2)\end{array}$ & $\begin{array}{l}<62 \\
(3)\end{array}$ & $\begin{array}{l}<62 \\
(4)\end{array}$ & $\begin{array}{l}\text { All } \\
(5)\end{array}$ & $\begin{array}{l}\text { All } \\
\text { (6) }\end{array}$ \\
\hline Unemp Kid & $\begin{array}{c}-0.136^{*} \\
0.065\end{array}$ & & $\begin{array}{c}-0.007 \\
0.008\end{array}$ & & $\begin{array}{c}-252.010^{*} \\
109.146\end{array}$ & \\
\hline Unemp Kid * Zero LS & & $\begin{array}{l}-0.05 \\
0.049\end{array}$ & & $\begin{array}{r}-0.007 \\
0.007\end{array}$ & & \\
\hline Unemp Kid ${ }^{*}$ Low LS & & $\begin{array}{c}-0.051 \\
0.032\end{array}$ & & $\begin{array}{c}-0.007 \\
0.005\end{array}$ & & \\
\hline Unemp Kid ${ }^{*}$ Mid LS & & $\begin{array}{c}-0.104 \\
0.096\end{array}$ & & $\begin{array}{c}-0.006 \\
0.012\end{array}$ & & \\
\hline Unemp Kid ${ }^{*}$ High LS & & $\begin{array}{c}-0.186 \\
0.1\end{array}$ & & $\begin{array}{c}-0.009 \\
0.014\end{array}$ & & \\
\hline Unemp Kid ${ }^{*}<62$ & & & & & & $\begin{array}{c}-205.626 \\
128.314\end{array}$ \\
\hline Unemp Kid * 62-70 & & & & & & $\begin{array}{l}-73.669 \\
216.791\end{array}$ \\
\hline Unemp Kid* $>70$ & & & & & & $\begin{array}{c}-910.941^{* *} \\
331.283\end{array}$ \\
\hline$X_{c t}$ & Y & Y & Y & Y & $\mathrm{Y}$ & Y \\
\hline$X_{p t}$ & $\mathrm{Y}$ & Y & Y & Y & Y & Y \\
\hline Year \& Age FE & Y & Y & Y & Y & Y & Y \\
\hline Individual FE & $\mathrm{Y}$ & Y & Y & Y & Y & $\mathrm{Y}$ \\
\hline Wealth Quantile & $\mathrm{Y}$ & $\mathrm{Y}$ & $\mathrm{Y}$ & $\mathrm{Y}$ & Y & $\mathrm{Y}$ \\
\hline Mean Dep. Var. & $0.66 \%$ & $0.66 \%$ & 0.122 & 0.122 & $\$ 35895$ & $\$ 35895$ \\
\hline $\mathrm{N}$ & 15242 & 15242 & 15242 & 15242 & 15242 & 15242 \\
\hline
\end{tabular}

Note: Standard errors listed. The six regressions shown include but do not show estimates for child covariates (marital status, disability status, birth of a child) and mother's household covariates (presence of an unemployment member, marital status, disability status, employment status, and local unemployment rate). 
Appendix A: Figures and Tables 


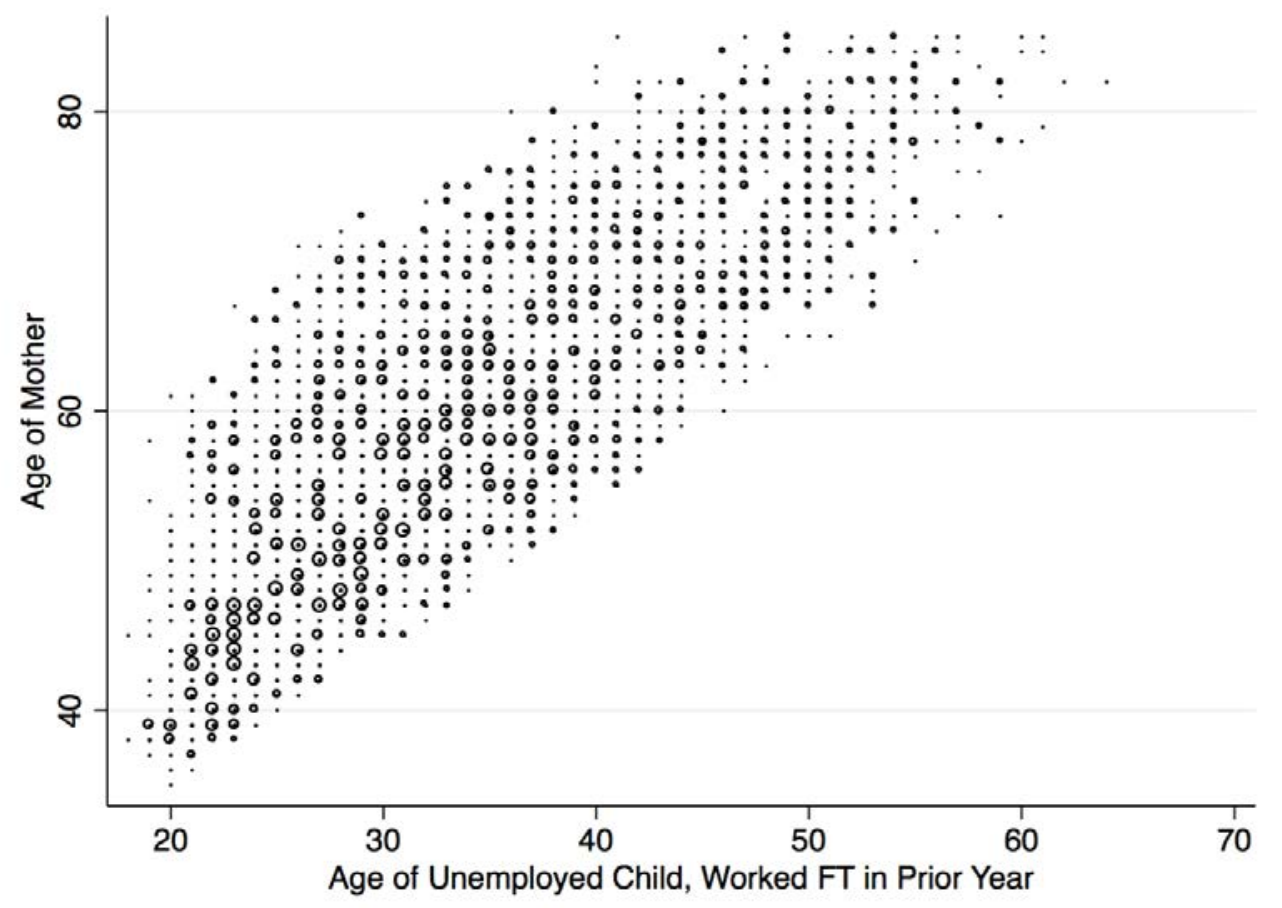

Figure A1. Age Pairs of Mother and Unemployed Child, PSID, 1985-2013 


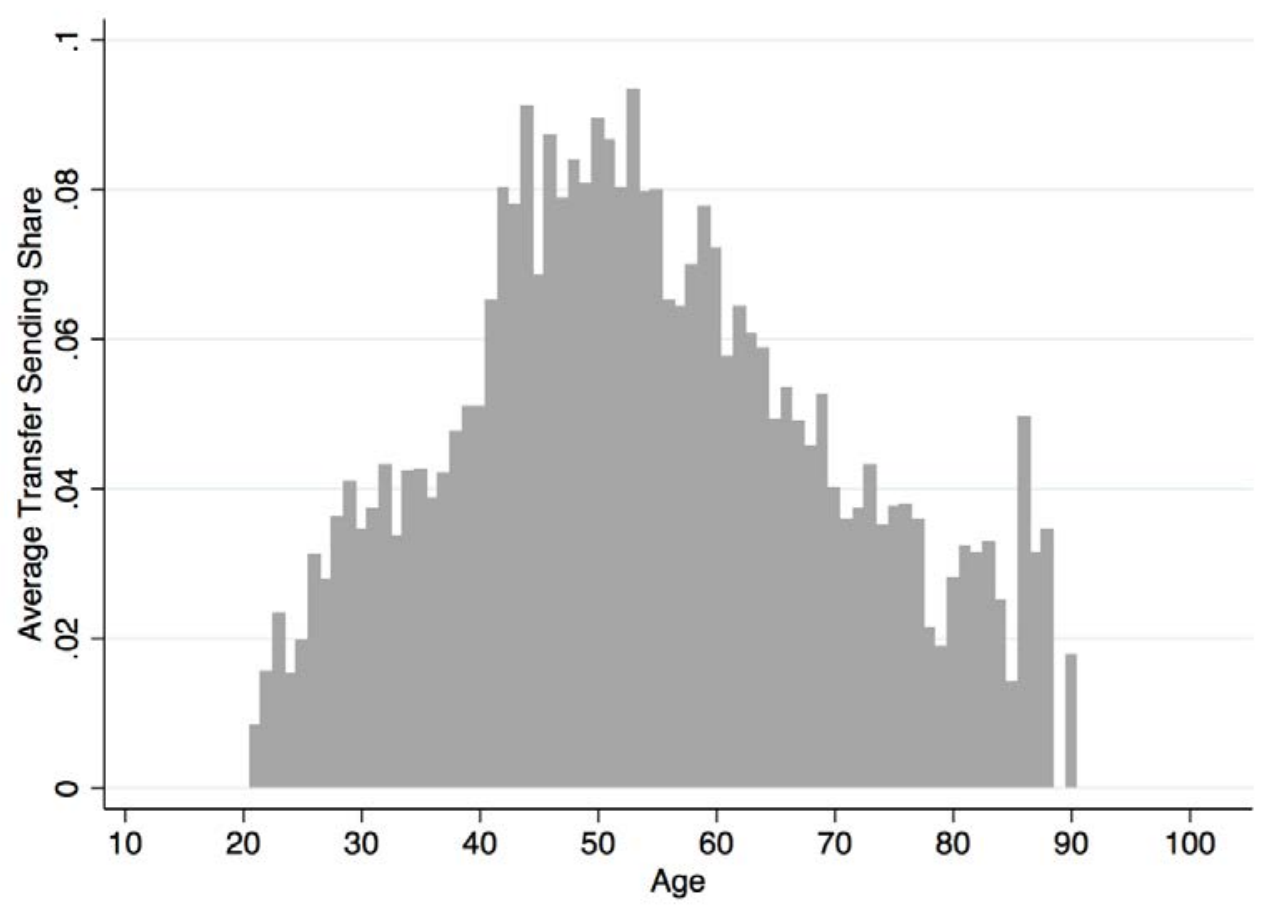

Figure A2. Share of Mothers Reporting a Transfer Sent to a Child, Average by Age, PSID, 1985-2013

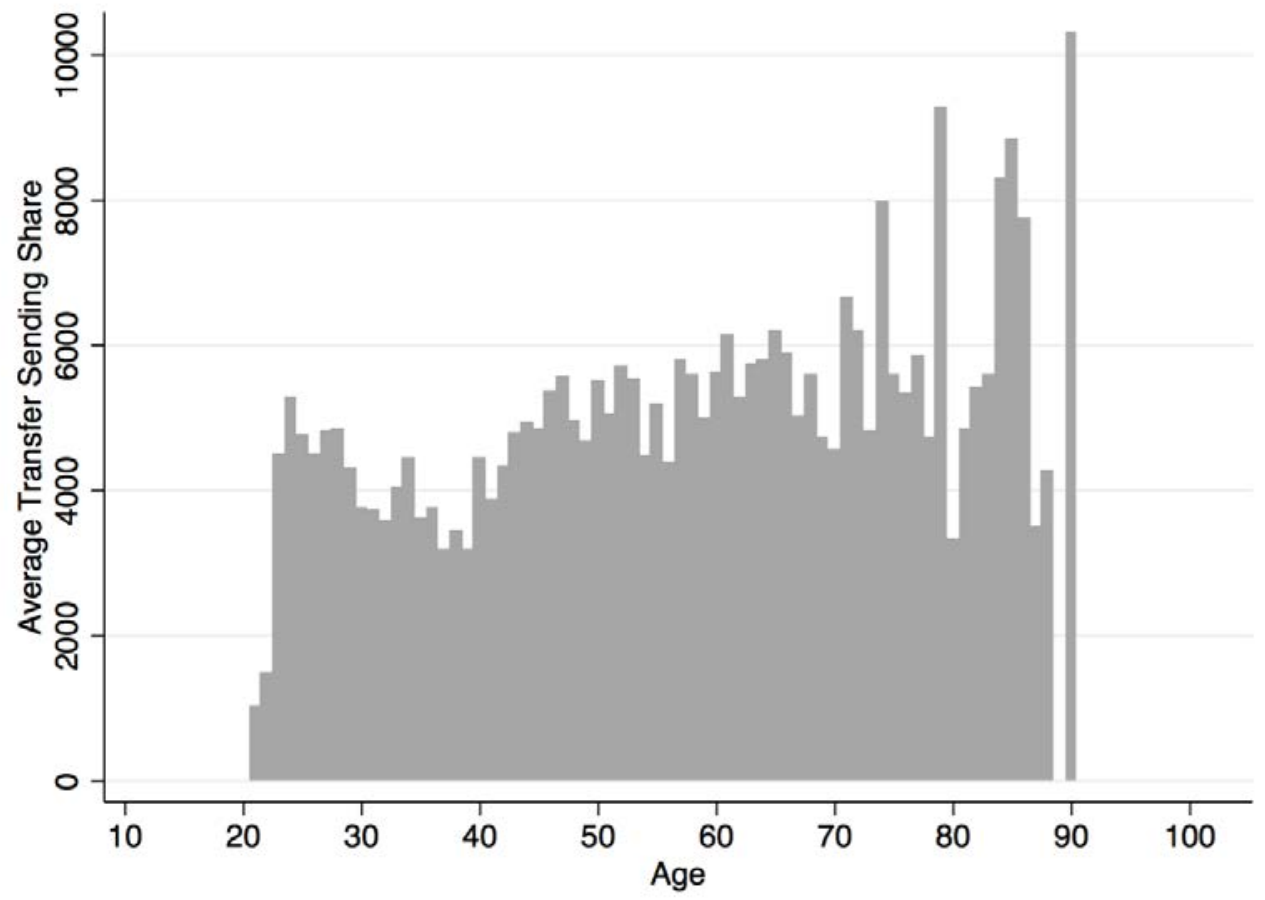

Figure A3. Size of Reported Transfers Sent to a Child, Average by Age, PSID, 1985-2013 


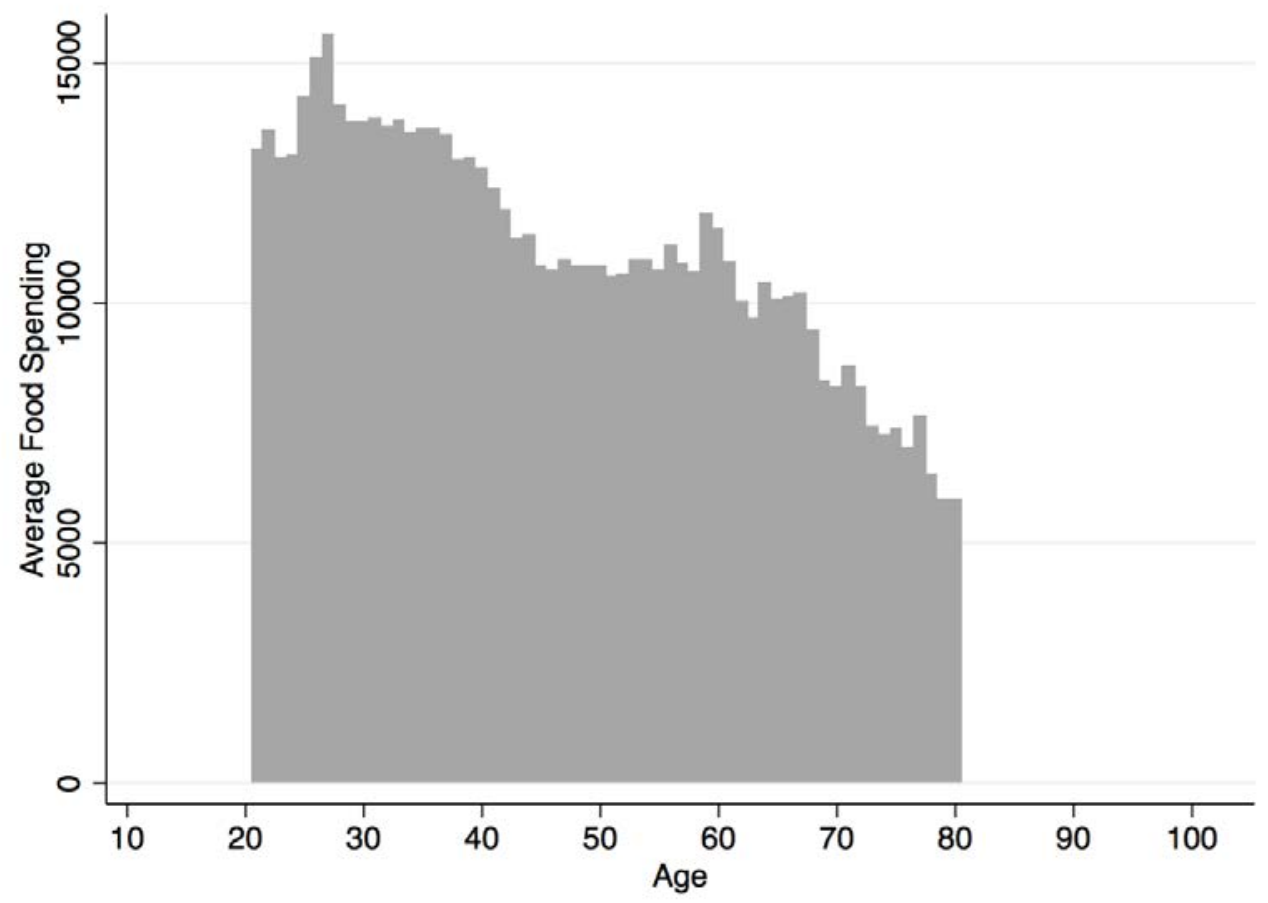

Figure A4. Usual Household Food Consumption, Average by Age, PSID, 1985-2013 


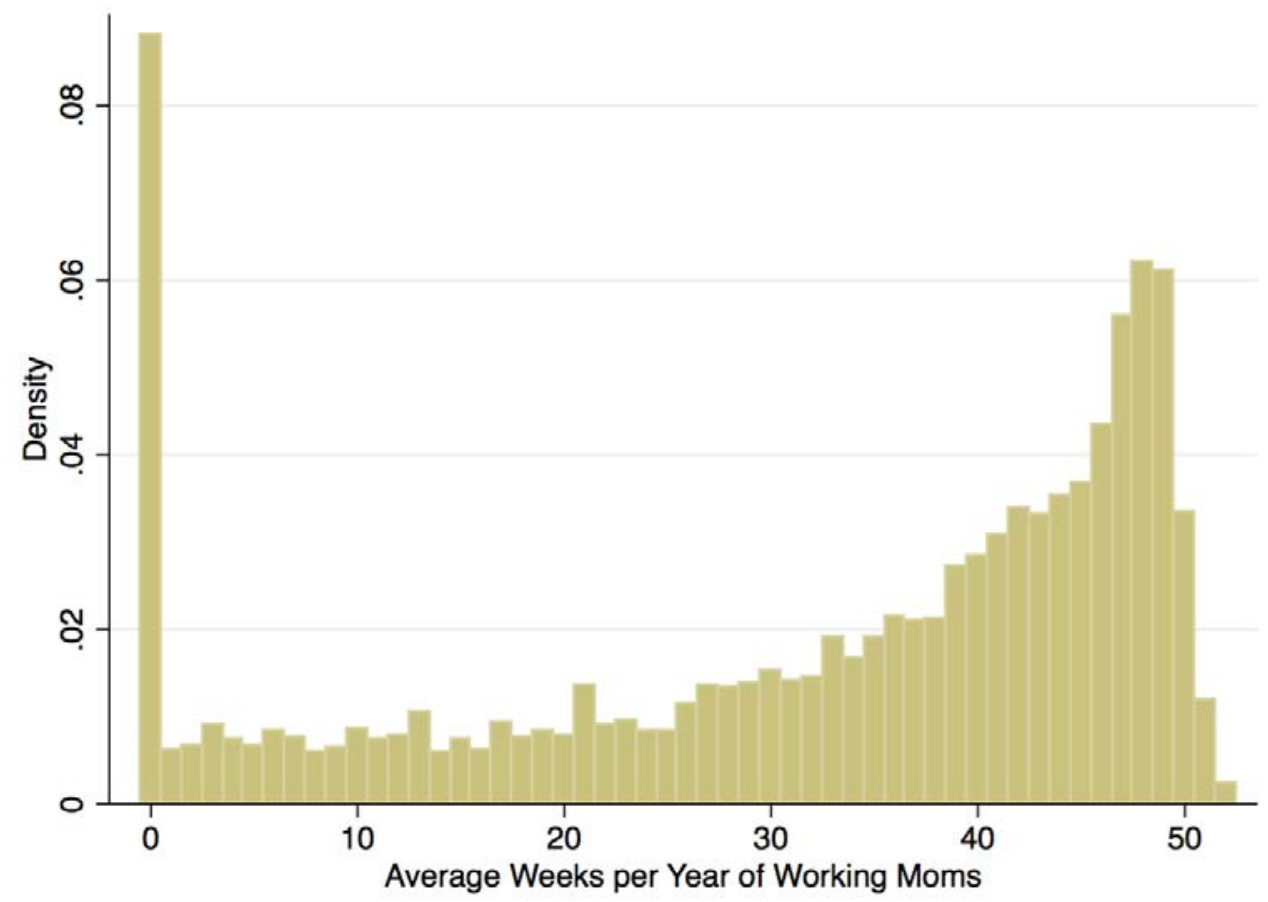

Figure A5. Histogram of Mother's Lifetime Labor Supply, Annual Average between Ages 30-60, PSID, 1985-2013

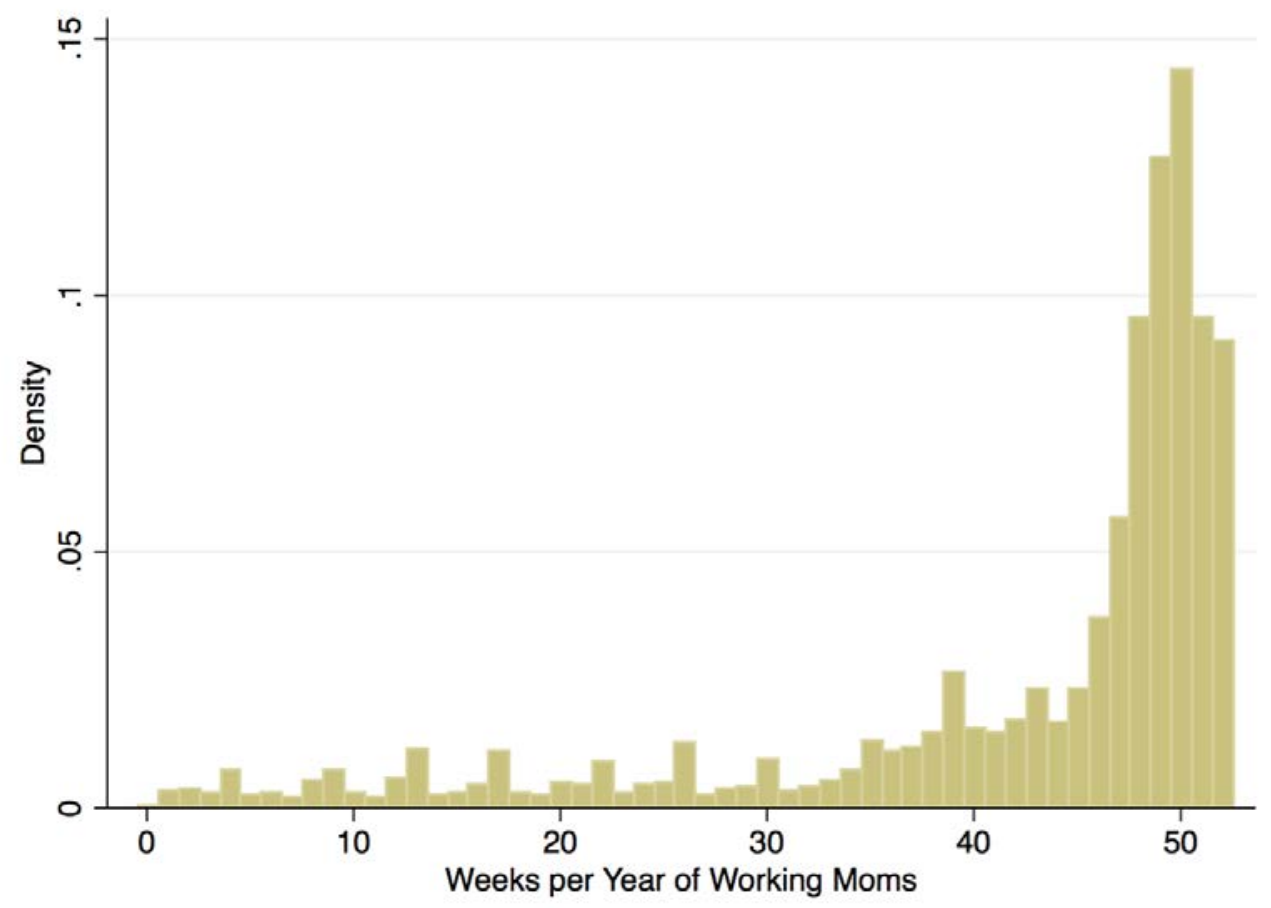

Figure A6. Histogram of Mother's Weeks Employed Per Year, Conditional on Positive Weeks, PSID, 1985-2013 


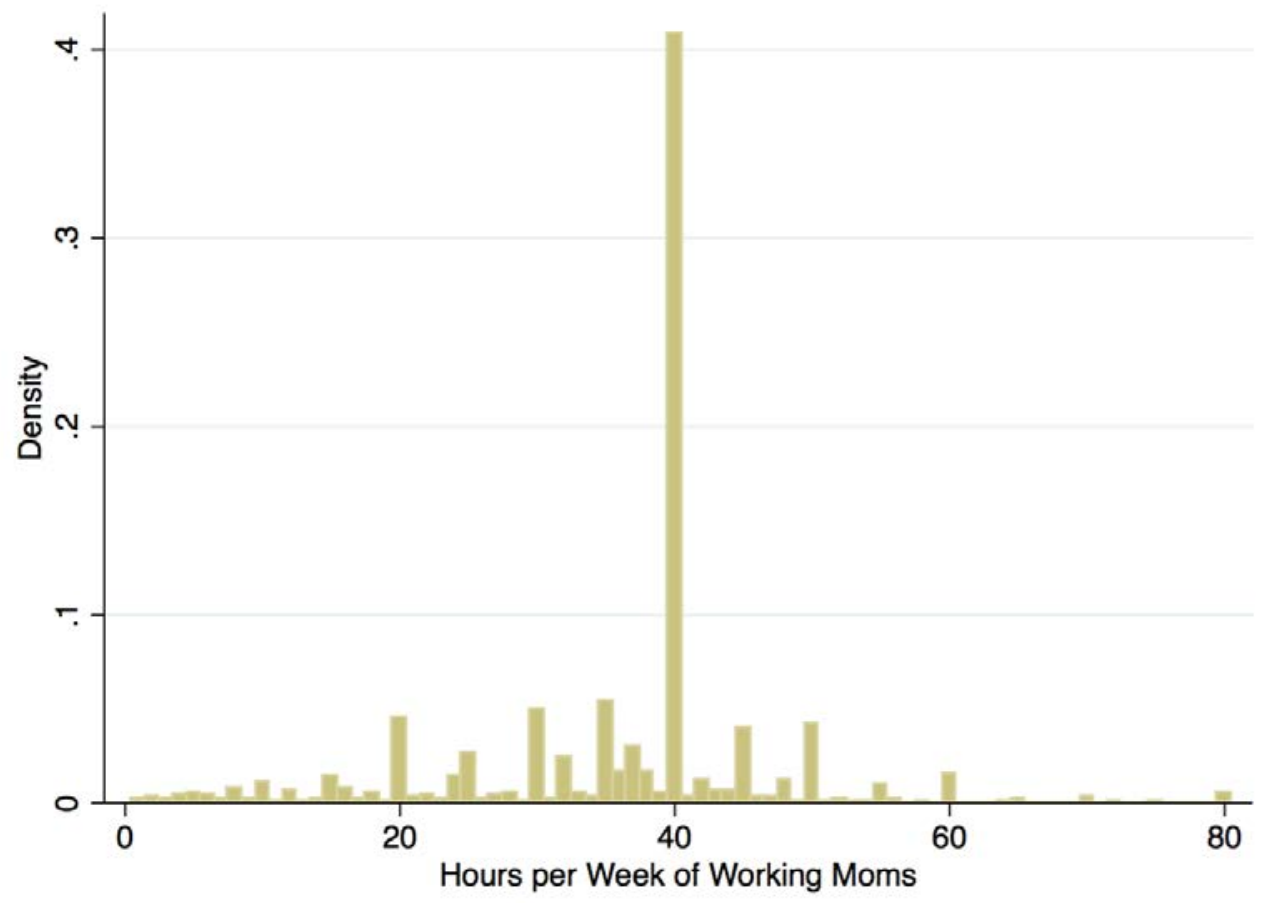

Figure A7. Histogram of Mother's Hours per Week, Conditional on Positive Hours, PSID, 1985-2013

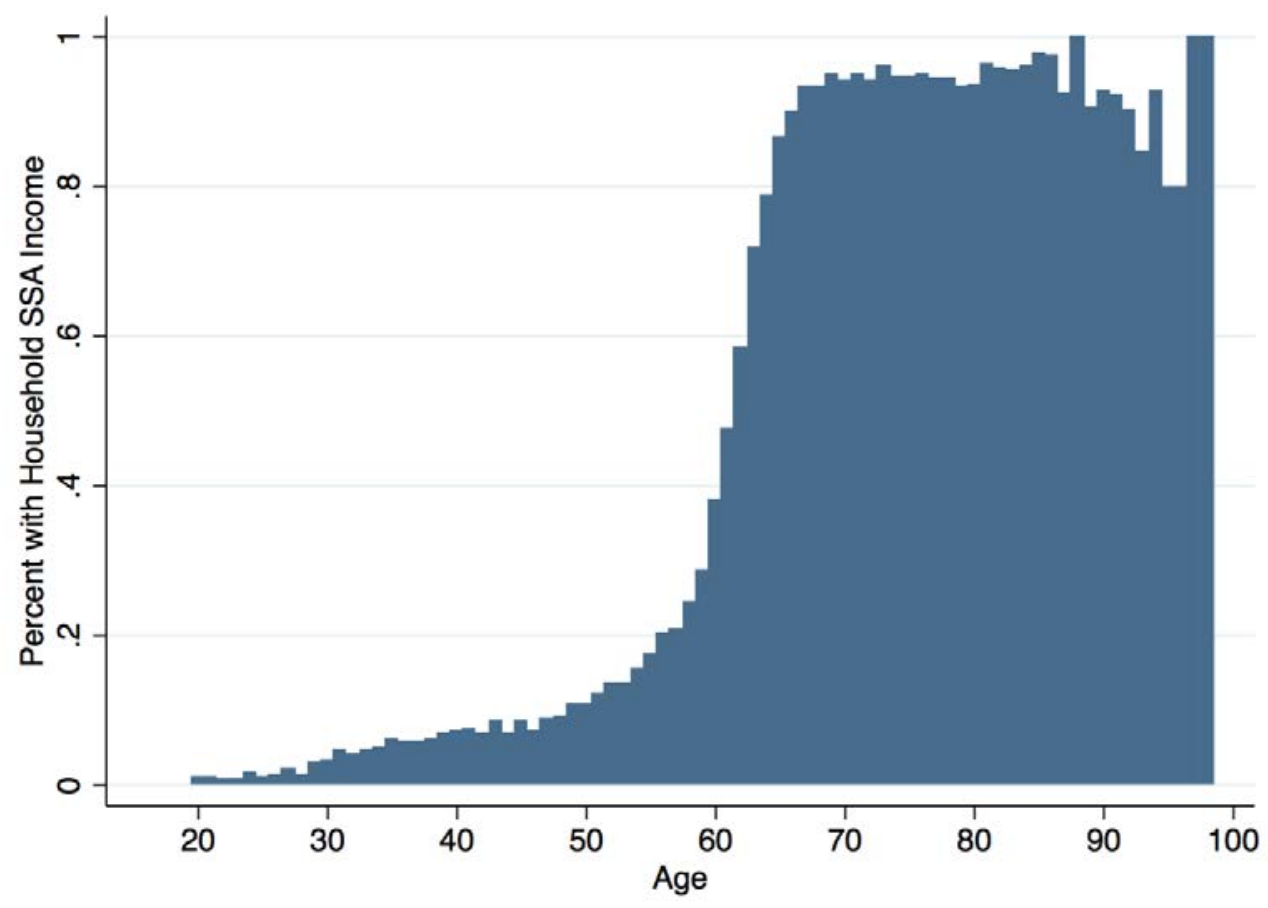

Figure A8. Share of Individuals in Households with Social Security Income, by Age 


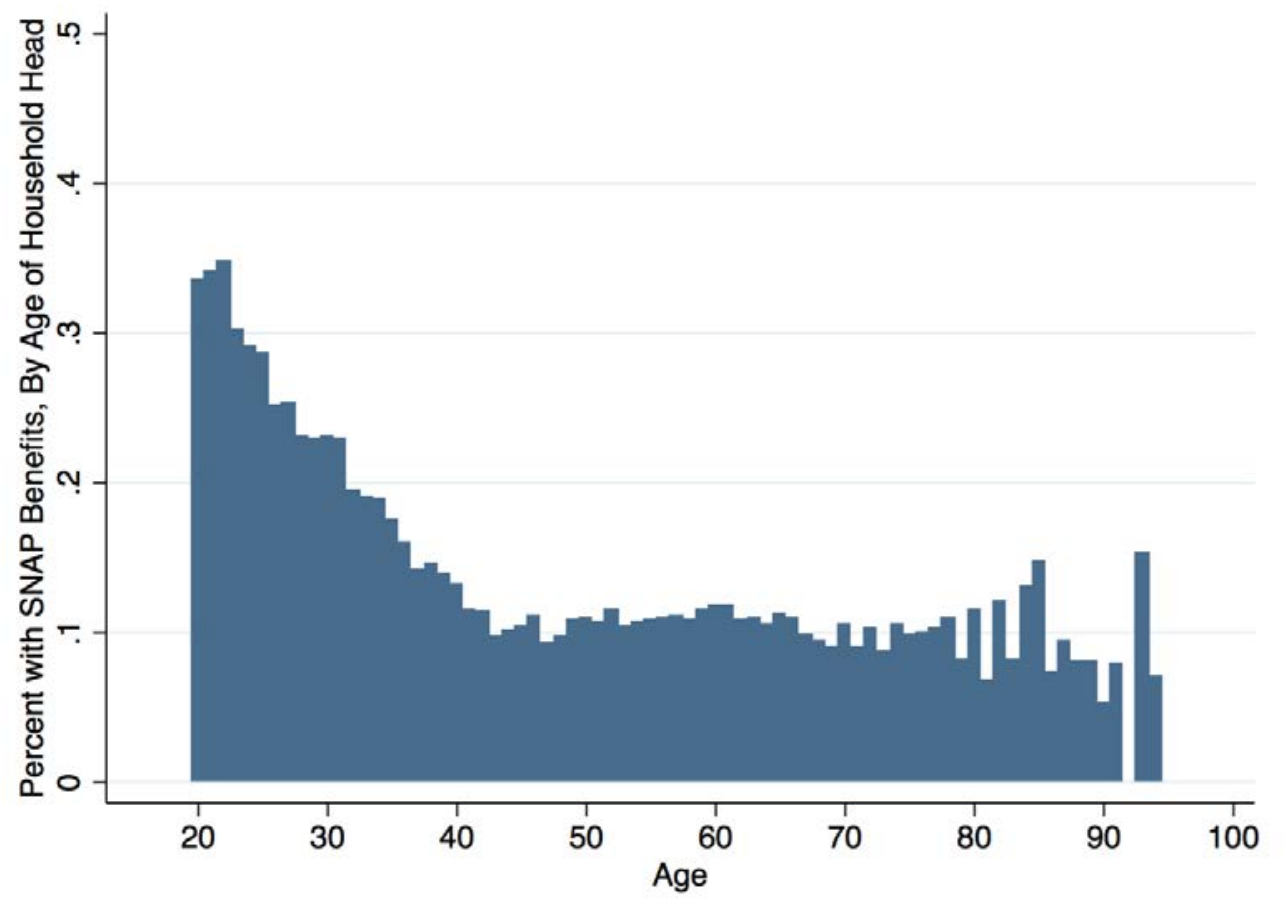

Figure A9. Share of Individuals in Households with SNAP Benefits, by Age

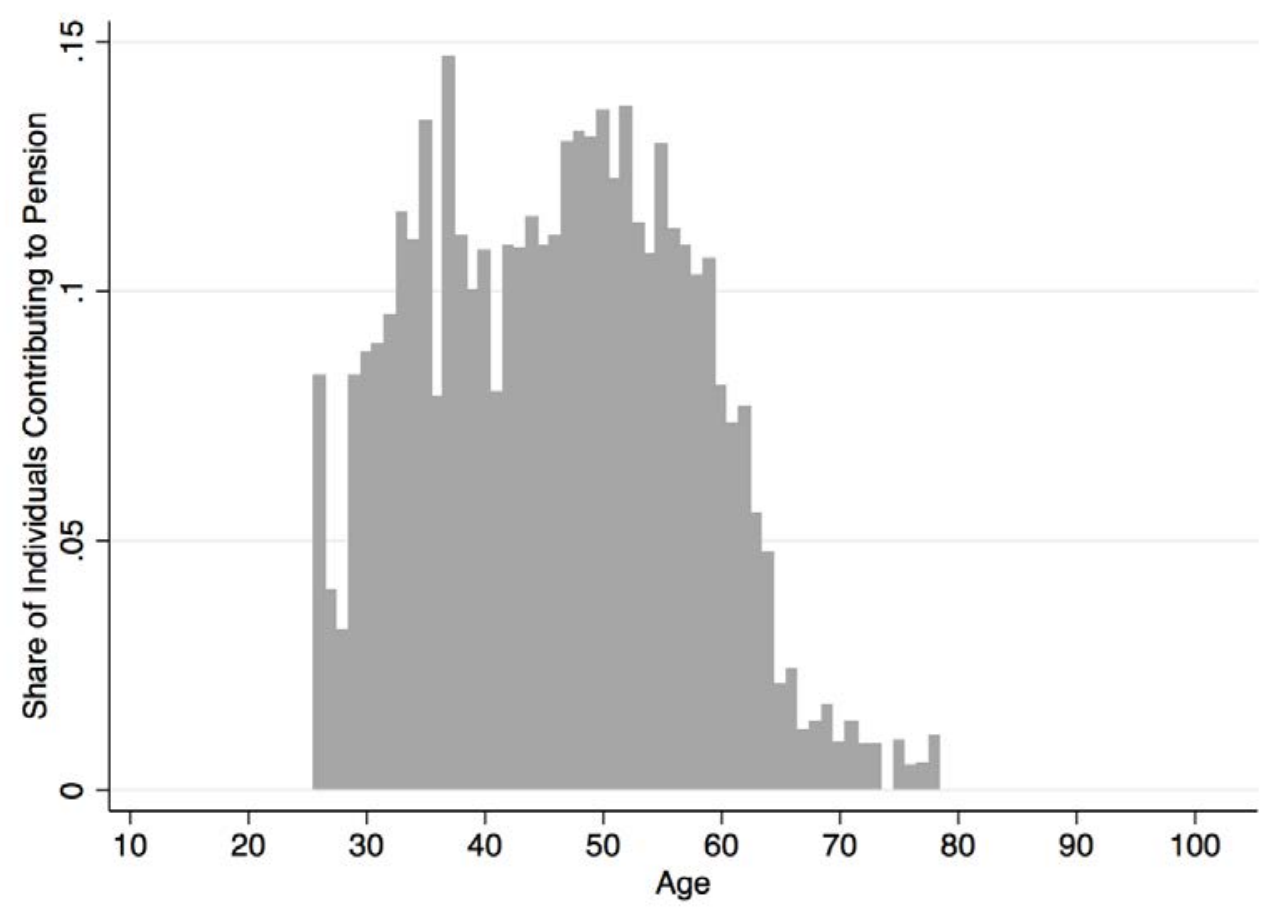

Figure A10. Share of Individuals Contributing to Pension, by Age 


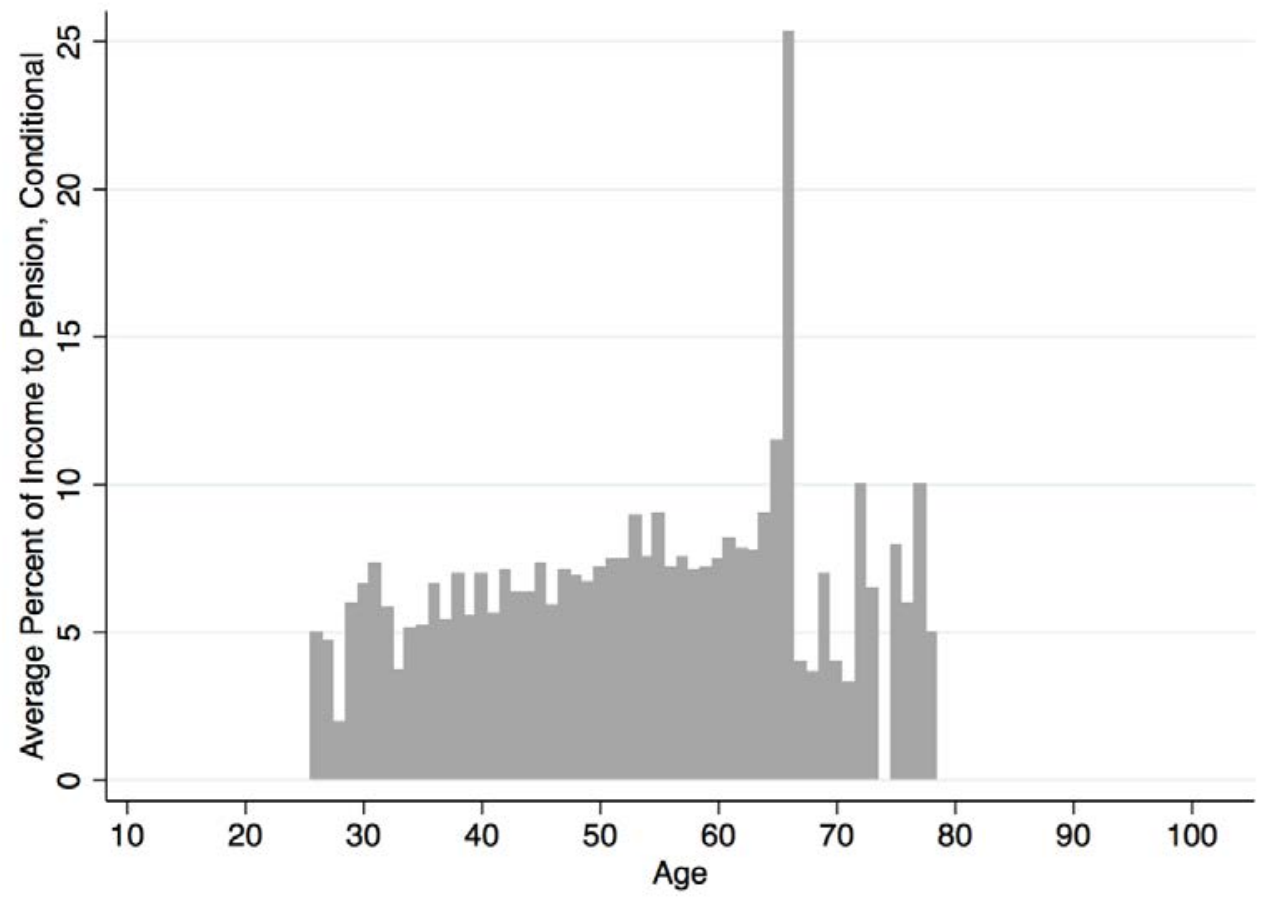

Figure A11. Conditional Share of Income Contributed to a Pension, Average by Age, PSID, 1999-2013

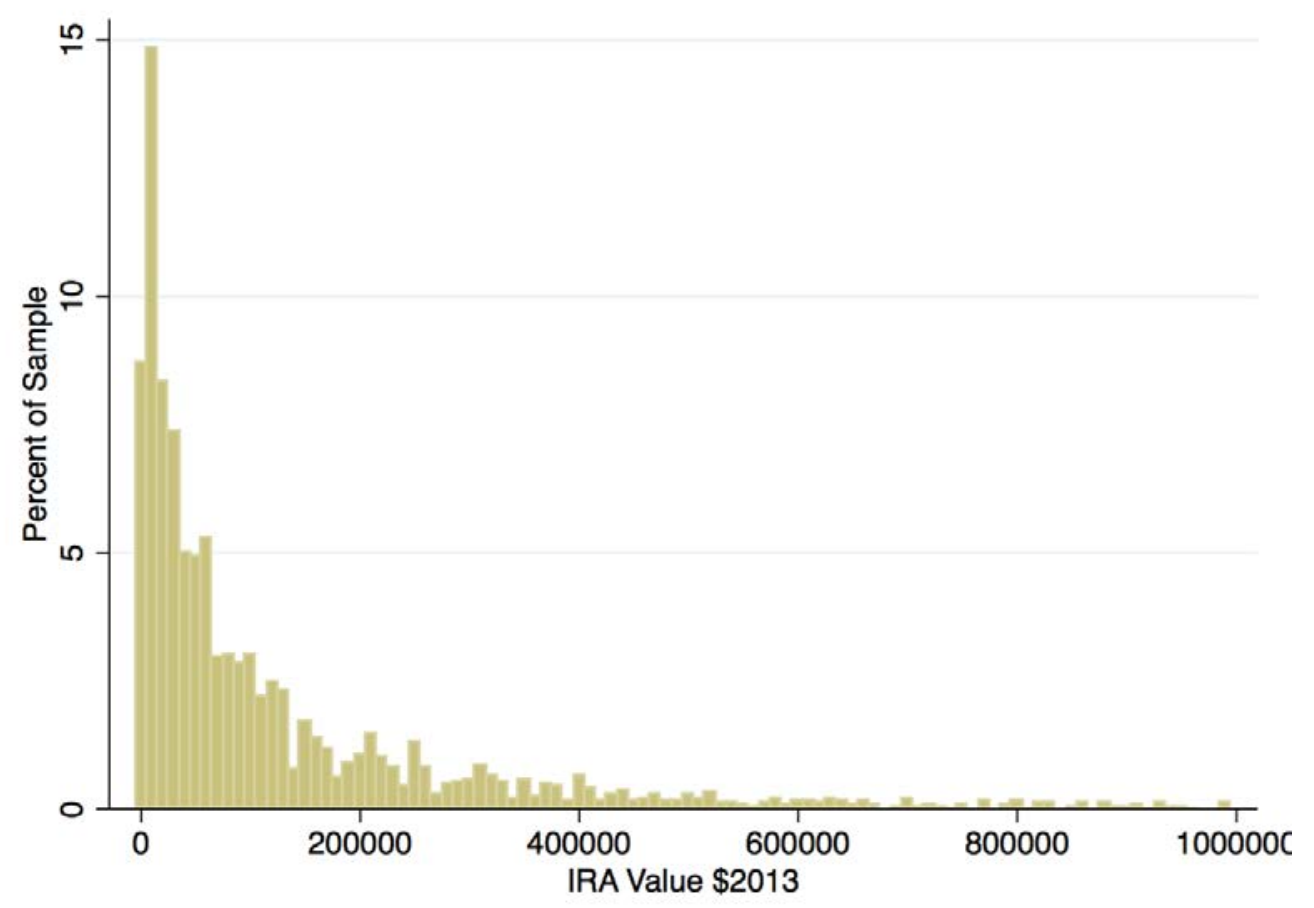

Figure A12. Histogram of Observed IRA Wealth 


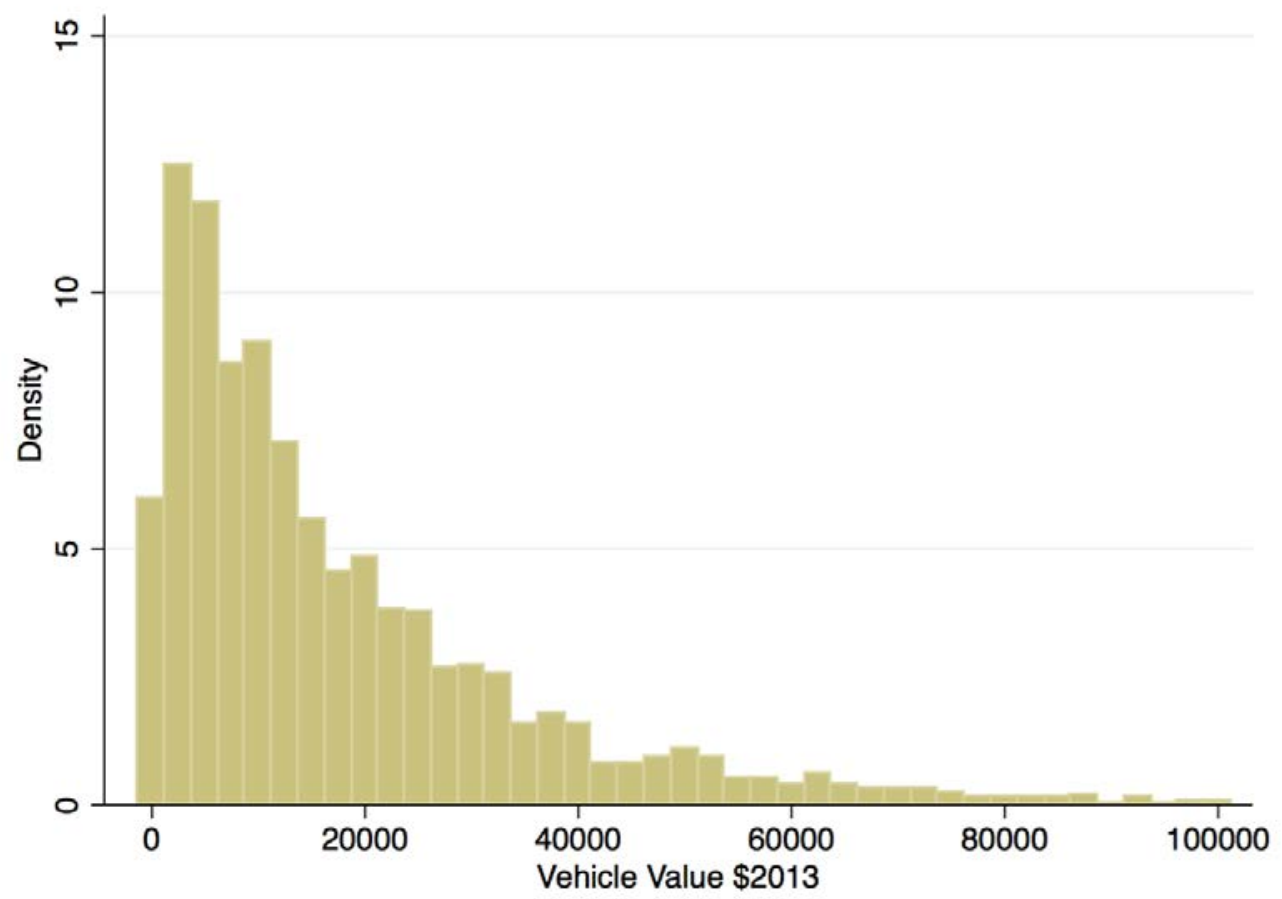

Figure A13. Histogram of Observed Vehicle Wealth 
Appendix Table 1. Sample Drops

\begin{tabular}{l|l|r} 
Target & PSID Group & N (person- \\
\hline $\begin{array}{l}\text { (i.) Individuals with } \\
\text { labor fbrce measures }\end{array}$ & Heads and Spouses & 314,200 \\
(iia.) Potential children & $\begin{array}{l}\text { Person number of mom } \\
\text { isgiven }\end{array}$ & 172,032 \\
(iib.) Potential mothers & $\begin{array}{l}\text { Female who indicates she } \\
\text { has/ had children }\end{array}$ & 52,653 \\
\hline $\begin{array}{l}\text { (iii.) Matched } \\
\text { observations } \\
\text { (iv.) Matched Moms }\end{array}$ & $\begin{array}{l}\text { Allobservationsofmother } \\
\text { has a matched child }\end{array}$ & 117,843 \\
$\begin{array}{l}\text { (v.) Years with transfer } \\
\text { recipient info }\end{array}$ & 1985-2013 & 69,541 \\
\hline (vi.) Kids living & & 38,004 \\
\hline
\end{tabular}

Note: The first drop (iia) reduces the sample to all independently living heads and wives in the PSID whose mother was ever in the sample; the second drop (iib) reduces the all women in the PSID who indicated they had at least one child; these two groups are matched into group (iii). The person-year matches are expanded to any observations of the mother (iv), the matched sample. From the matched sample, (v) reduces the sample to moms who are observed after 1985 and (vi) to those person years in which at least one child who lives in a separate residence. 
Appendix Table2. Summary of Women 40-80 years old in the PSID by child match and motherhood

\begin{tabular}{|c|c|c|c|}
\hline & $\begin{array}{l}\text { Matched } \\
\text { Moms } \\
\text { N=35919 }\end{array}$ & $\begin{array}{l}\text { Unmatched } \\
\text { Moms } \\
\text { N=27375 }\end{array}$ & $\begin{array}{c}\text { Remaining } \\
\text { Women } \\
\mathrm{N}=8791\end{array}$ \\
\hline Age & 62.0 & 51.3 & 56.7 \\
\hline Min Observed Age & 34.9 & 29.6 & 35.5 \\
\hline Max Observed Age & 68.0 & 57.8 & 61.0 \\
\hline White & 0.744 & 0.709 & 0.738 \\
\hline Black & 0.134 & 0.115 & 0.104 \\
\hline High School orLess & 0.696 & 0.432 & 0.371 \\
\hline SomeCollegeorMore & 0.298 & 0.565 & 0.604 \\
\hline Married & 0.596 & 0.676 & 0.443 \\
\hline Divorced/Sep. & 0.194 & 0.196 & 0.118 \\
\hline Never Married & 0.029 & 0.053 & 0.333 \\
\hline Widow & 0.180 & 0.074 & 0.106 \\
\hline Disabled & 0.045 & 0.030 & 0.062 \\
\hline Housewife & 0.145 & 0.132 & 0.086 \\
\hline Working & 0.456 & 0.671 & 0.587 \\
\hline Sent Transfer to Kid & 0.072 & 0.041 & 0.037 \\
\hline Size of Transfer to Kid & $\$ 336$ & $\$ 214$ & $\$ 198$ \\
\hline Received Transfer & 0.051 & 0.073 & 0.059 \\
\hline Size of ReceivedTransfer & $\$ 159$ & $\$ 287$ & $\$ 216$ \\
\hline Weeks Worked & 23.2 & 33.1 & 28.6 \\
\hline Weeks Unemployed & 1.1 & 1.6 & 1.0 \\
\hline Receiving SSA Income & 0.510 & 0.207 & 0.322 \\
\hline ReceivingSNAP & 0.061 & 0.063 & 0.048 \\
\hline Usual Food Consumption & $\$ 6904$ & $\$ 9235$ & $\$ 6576$ \\
\hline Contribute to a Pension & 0.071 & 0.110 & 0.125 \\
\hline Percent of IncomeCont. & 0.537 & 0.784 & 1.025 \\
\hline Ever Contributed to Pension & 0.204 & 0.296 & 0.283 \\
\hline VehicleValue & $\$ 17,181$ & $\$ 18,037$ & $\$ 16,536$ \\
\hline IRA Value & $\$ 69,016$ & $\$ 40,668$ & $\$ 62,113$ \\
\hline
\end{tabular}

Source: Authors' Calculations of PSID data. Table excludes women who are younger than 40 or older than 80 years old. Matched mothers are linked via family id and person number to a child's observation in at least one wave. Unmatched mothers indicated in survey response that they had at least one child, but was not matched to a separate child observation. Sample weighted using core weights. 


\section{Appendix B: Matching Family Members}

Appendix A: Table 1 details the parent-child matching process. The PSID has 410,524 person-year observations of heads and spouses, which as mentioned, are the set of individuals for whom annual labor force variables are measured. That initial group (i) can be split into two sides of the match (not mutually exclusive), those individuals who have had a mother in the PSID at some point of the survey and whose person number is given (iia) and females who indicate in the survey that they have had a child (iib). Note that this includes each wave that the person was in the PSID for both potential children and potential mothers, down to age zero. Of the 314,200 person-year kids and 172,032 person-year potential mothers, 52,653 observations are matched (iii). When the matched person-year observations are expanded to include all the years the mother was observed (iv), the observations reach 117,843, a match rate of 68.5 percent. That share is not to be interpreted too strictly, as not all mothers are mothers the entire length of the PSID for which they are observed, nor will all individuals with mothers will have mothers alive and living in a separate household for every year the individual is observed.

There are two additional cuts to the matched mother-kid sample. The first is due to question design. Although a measure of money transferred out of the household to family is available in all years of the survey, the recipient type (child, sibling, parent, etc) is not introduced until the 1985 wave, hence the prior years are dropped (iv). Second, we want to see detailed labor force measures of the child in order to identify unemployment spells, meaning the child must be living as a head of household and apart from her mother. For this reason, we drop all mother observations in which the child is not living separately (v). Our sample is thus 38,004 personyears of mothers with independently living children. We do not match fathers, primarily because the mother's observation includes the detailed information for the head of household, if it is not 
herself. ${ }^{23}$ Given the practice of survey inclusion in the PSID, we are at risk of losing information on male single parents, but that is a very small population.

To show the representativeness of the analytical sample, a comparison of matched mothers, women who indicated that they had children but who were unmatched, and remaining females is shown in Table 2. We limit the age of the compared women to when they are 40-80 years old, since that is approximately the age span of our sample. ${ }^{24}$ Matched mothers are older than unmatched mothers; the average age of matched mothers in column 1 is 62 years old, compared to 51.3 for unmatched mothers and 56.7 for remaining women. Matched mothers are also observed at older ages, the minimum and maximum age at which they are observed in the PSID range on average from 34.9 to 68 , compared to 29.6 to 57.8 for unmatched. This makes intu- itive sense, matched mothers have independently living children, which makes them older than mothers with children still at home. The age difference between matched and unmatched mothers explains many of the remaining demographic differences between the groups.

Across all three sets of women, there are similar shares of white individuals $(74.4,70.9$, 73.8 percent). Matched mothers, however, have less education than unmatched mothers, with 69.6 percent having a high school degree or less, compared to 43.2 percent for unmatched mothers and 37.1 percent for remaining women. This suggests that our sample is not only observed at older ages but also in earlier time periods, relative to the rest of the women in the PSID, and is important for interpreting our results. It is not surprising then that, given that matched mothers are older and observed earlier, 59.6 percent of matched mothers are married, a lower share than the 67.6 percent of unmatched mothers and 44.3 percent of remaining women, but have a much higher share of widows, at 18 percent, compared to 7.4 percent and 10.6 percent. In addition, a much lower share of matched mothers are working (45.6 percent) than unmatched

\footnotetext{
${ }^{23}$ The PSID assigns head and spouse by gender; heads are male and spouses are female, unless a woman is living alone, in which case she can be a head.

${ }^{24}$ This slightly reduces the sample of matched mothers from Table 1 by dropping very young and very old mothers.
} 
(67.1 percent) and remaining women (58.7 percent).

The bottom half of Appendix Table 1 summarizes the dependent variables used in this analysis. Differences across matched mothers, unmatched mothers, and remaining women can be mostly attributed to age differences. 